\title{
TEATRO CRÍTICO LATINOAMERICANO: ELEMENTOS TEÓRICOS PARA DESARROLLAR UN CAMPO DE INVESTIGACIÓN $^{1}$
}

\author{
César de Vicente Hernando ${ }^{2}$
}

\section{Resumen/Abstract}

Este artículo intenta establecer un plan de estudio del teatro crítico latinoamericano definiendo el objeto de investigación a partir de varios conceptos fundamentales: teatro, ritual y teatralidad, identidad, historicidad, cultura, etc. El elemento central es el discurso crítico, que no es una opinión, ni un comentario, ni una valoración, sino un procedimiento de objetivación de los textos teatrales y de las realizaciones escénicas mediante el que se analizan las condiciones de producción de las obras. La capacidad explicativa del discurso crítico procede de su permanente ruptura con la moral, la ideología y la tradición. Contra la elaboración académica de las historias del teatro, la separación por países, por géneros y por temáticas, el corpus de obras de teatro crítico latinoamericano que se busca aquí, está en relación con elementos transversales que afectan a varios países y que están determinados por los procesos históricos. Una propuesta de análisis de Los invasores, de Egon Wolff, muestra los resultados de tal planteamiento.

Palabras clave: discurso crítico. historicidad. historia del teatro. Latinoamérica

This article tries to establish a plan of study of the critical Latin-American theatre defining the object of research from several fundamental concepts: theatre, ritual and theatricality, identity, historicity, culture, etc. The central element is the critical discourse, which is neither an opinion, nor a comment, nor a valuation, but a procedure of objectivation of the theatrical texts and of the scenic performance by means of that are analysed the conditions of production of the works. The explanatory capacity of the critical discourse comes from his permanent break with the morality, the ideology and the tradition. Against the academic elaboration of the histories of the theatre, the separation for countries, for genres and for subject matters, the critical Latin-American theatre corpus of plays that is looked here is in relation with elements of the transversality that concern to several countries and the

\footnotetext{
1 Este texto recoge, corregido y ampliado, las tres sesiones que preparé para la Academia Universidad del Humanismo Cristiano los días 17, 18 y 19 de noviembre de 2014.

${ }^{2}$ Español. Centro de Documentación Crítica. E-mail: noviembre@nodo50.org
} 
historical processes determine that. An offer of analysis of Egon Wolff's Los invasores, it shows the results of an approach like that.

Keywords: critical discourse. Historicity. History of the theatre. Latin America

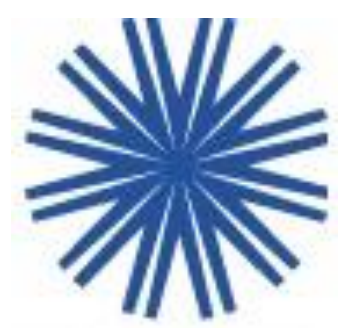

Uno de los problemas fundamentales para la teoría y la historia del teatro es la consideración de qué se incluye en este campo de la ideología, cómo se incluye y en función de qué criterios se define el numeroso y diverso material que denominamos obras teatrales, más aún teniendo en cuenta que las obras teatrales están delimitadas hasta por tres marcos temporales y contextuales distintos: por la fecha de escritura de las obras, por la fecha de publicación y por la de representación. Una obra como la que tomaremos como ejemplo en este texto, Los invasores de Egon Wolff, no puede ser analizada como un único texto desde el mismo momento en que sufre dos mediaciones más, aparte de la histórica procedente de su escritura (o sea, su clase social escribiendo en un momento dado, etc.): la de la publicación, al convertirse en un clásico con su aparición en antologías como "Teatro chileno contemporáneo" o "Teatro selecto chileno" etc. en volúmenes homónimos publicados por Aguilar en 1970 y RIL editores en 2002, además de muchas otras ediciones, así como la de sus diferentes montajes en los que la dirección escénica impone una lectura nueva para un contexto distinto a aquel en la que se concibió.

Hasta ahora, las historias del teatro seguían un principio de ordenación cronológica, generalmente diferenciando el teatro desarrollado en los distintos territorios nacionales, y tomando como corpus fundamentalmente las obras realizadas por autores. Los programas académicos han reproducido esta concepción teórica de clasificación y periodización, reafirmando el valor de la misma y sistematizándolo ampliamente ${ }^{3}$.

Parece necesario, después de un siglo de crítica materialista (marxismo, feminismo, poscolonialismo, etc.) que ha mostrado los callejones sin salida del idealismo, intentar cambiar radicalmente estos

\footnotetext{
3 En el caso de la literatura también ha sido así. En España, incluso la Historia social de la literatura española sólo pudo introducir criterios sociales, políticos, económicos e ideológicos en la historización, pero mantenía el criterio cronológico como central.
} 
criterios que se han visto insuficientes, desde una perspectiva explicativa, y arbitrarios, para la comprensión de las razones de los cambios producidos, y plantear una concepción diferente que abandone los tres ejes centrales del discurso idealista: el autor, la época y la obra, como conocimientos positivos que producen la ilusión de un saber inmediato, en beneficio de otros derivados de un discurso materialista ${ }^{4}$ : espacio de la producción, producto y espacio de resolución. En términos históricos, podríamos igualmente, buscar formas de conocimiento que, si bien consideran las condiciones sociales específicas en que aparecen las obras teatrales, no olviden tampoco que, en un cierto sentido, el arte no tiene historia ${ }^{5}, y$, por tanto, que los géneros, las estéticas, etc. pueden aparecer, y de hecho aparecen, en tiempos históricos distintos (el sainete, por ejemplo, sigue siendo ochenta años después una forma estética actual). Un paso inicial hacia este nuevo campo de investigación es su delimitación teórica, que es lo que vamos a intentar aquí. Sin embargo, no tratamos de establecer los fundamentos para una nueva historia del teatro latinoamericano, sino de definir un campo de investigación e historización que denominamos Teatro Crítico Latinoamericano y que incluye todas aquellas obras que deriva de un discurso específico analítico materialista.

\section{Los tres ámbitos}

Resulta, pues, necesario empezar dando cuenta de a qué nos referimos con tal denominación: Teatro, Crítico, Latinoamericano. En primer lugar, encontramos tres ámbitos que permiten explicar las formas teatrales (dibujo 1) que se dan específicamente en el panorama teatral latinoamericano. Convergen tres términos que se relacionan en sus vértices, pero no en su totalidad. El primero es el teatro, la forma

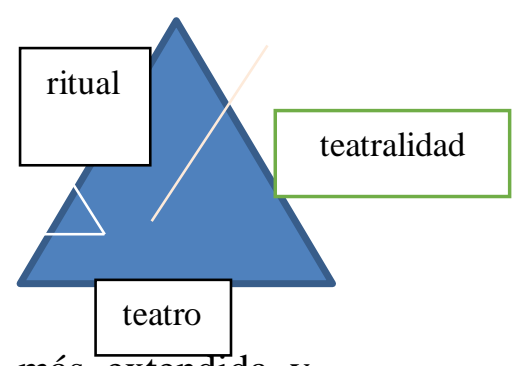
hegemónica en el modelo de las historias positivistas del teatro. Se considera esta forma en tanto que autónoma y dependiente de las normas y principios del modelo clásico y moderno del teatro. Esta idea del teatro se caracterizaría por tratarse de un discurso y una práctica que divide el espacio escénico y el espacio del espectador; que desarrolla una fábula y que

\footnotetext{
4 Como el que presentaron hace algunos años Pierre Macherey en Para una teoría de la producción literaria (1966) y José Luis Ángeles en Hacia una ideología de la producción literaria (2000).

5 Tal y como Louis Althusser decía que la ideología no tiene historia en Curso de filosofía para científicos (1967).
} 
establece unos límites estéticos definidos por un tiempo específico, una palabra dramática y unos personajes. Esto es lo que se estaría dando en la mayoría de los teatros en Latinoamérica, y siendo reconocido como teatro. En realidad, es también lo que se concibe en Europa como el teatro burgués, el que establece una clase social en un momento dado, y que traslada al resto de los países y sociedades. Es $s u$ teatro, pero lo define, con afán universalista, como el teatro. Para conseguir este estatuto ha sido necesario hacer antes un trabajo muy intenso y muy complejo de desactivación de lo que son las otras dos formas que estaban funcionando en las sociedades en las que se desarrolla triunfante la burguesía, cuando este proyecto se instala en las repúblicas independizadas de Latinoamérica. Lo que hace esa clase ascendente burguesa es imponer la problemática, el objeto y la metodología de su teatro (del teatro burgués), y esto es lo que tenemos hasta nuestros días. Este teatro intenta poner fuera de juego otras formas que funcionaban en esas sociedades: lo que se señala en uno de los ejes como ritual. El ritual, que está en discusión sobre si es propiamente teatro o no, tiene una serie de elementos espectaculares, como máscaras, escenogramas, acciones, etc. (lo que le asemejaría con el teatro), pero, en realidad, se trata de una ceremonia o actividad social en la que el espectador en realidad no es tal sino que participa como creyente, en donde se repite un relato colectivo (no existe propiamente la fábula), y que no se representa sino que se vive (lo que lo relacionaría con la teatralidad). Esto es muy importante porque toda la historia del teatro latinoamericano puede entenderse en su complejidad si tenemos en cuenta esta progresiva sustitución del ritual por un teatro colonial humanista-religioso como el de Juan Pérez Ramírez y su Depositario espiritual (1574) o el de Juana Inés de la Cruz con El divino narciso (1689), y después por un modelo burgués como el de Gertrudis Gómez de Avellaneda, Manuel Eduardo de Gorostiza o Florencio Sánchez, así como la persistencia y reactivación del ritual y las teatralidades. De la misma manera, cuando se ha pretendido rescatar lo que se ha llamado los teatros prohibidos u ocultos de las comunidades indígenas, como ocurre con el teatro mapuche, en el caso de Chile; o del teatro campesino, en el caso de México, lo que se da cuenta es de un proceso de hibridación entre ese mismo teatro burgués dominante y una representación del ritual que recompone los elementos del mismo, por ejemplo, en una forma generalmente mercantilizada, de consumo. Es lo que Néstor García Canclini denomina “celebrar, recordar, vender" en su Las culturas populares en el capitalismo. La apropiación del ritual pasa a ser lo que García Canclini llama mercantilismo 
o museo. Se trata, entonces, de mostrar, en efecto, que hay unas identidades indígenas, que esas identidades tiene una serie de características, y para eso lo que se hace es potenciar un teatro indígena que nos señale y muestre sus ritos, pero en el marco del teatro burgués. Lo que sucede también es que a partir de esas diferencias que existen entre el teatro y los rituales también se pueden generar lo que se llaman teatralidades, intervenciones, instalaciones, acciones performativas, generalmente urbanas, que renuncian a la escena separada del teatro, no promueven una creencia, sino que consolidan a un espectador incluido, abandonan generalmente el diálogo dramático, pero mantienen procedimientos escénicos propios del teatro. Las teatralidades aparecen como un dispositivo que sirve para problematizar determinados aspectos de la vida social, y que se sirven también de elementos del ritual para poder utilizar el marco teatral sin las normas convencionales que lo rigen.

Las conexiones entre ritual, teatro y teatralidad, que en buena medida están relacionadas con la serie ceremonias, teatro dramático-teatro posdramático y performatividad, suponen ya una dificultad en cómo establecer el corpus del Teatro Crítico Latinoamericano, y que ya nos advierte que debe pensarse no sólo como una historia de la literatura dramática, de las obras teatrales, evidentemente, sino también de los textos escénicos. Las diferencias deben ser incorporadas en el procedimiento analítico: si el teatro se entiende como un espacio convencional, en el que público y actores son separados, en donde se desarrolla una fábula; en el ritual ese espacio es sacralizado al hacer la ceremonia donde se desarrolla una creencia, y en las teatralidades ese espacio se difumina, se realiza en lugares no convencionales como la calle, una plaza, un museo. Mientras que en el teatro uno reconoce el espacio escénico como el lugar donde se desarrolla la acción, en las teatralidades el espacio de acción es todo; de hecho, no existe ningún lugar privilegiado para la acción dramática. Si en el teatro aparecen dispositivos reconocibles que establecen significaciones convencionales prestablecidas como las luces, los decorados, en el ritual y en las teatralidades hay dispositivos, que pueden ser sonoros, visuales, en todo caso sígnicos, que se vinculan a cuestiones de la vida cotidiana y no de la representación propiamente. Fundamental, si el teatro establece una serie de mecanismos para que exista una ilusión dramática, para que sea creíble lo que sucede, para que el espectador pueda vincularse intelectual y emotivamente al espectáculo, en el ritual se produce una alucinación y en las teatralidades una visión. Mientras 
que en el teatro o en el ritual existe una convención que determina cuándo empieza y cuándo acaba la representación, en las teatralidades los participantes no conocen lo que se está desarrollando, o no saben dónde empieza y dónde acaba, participa de una manera autónoma porque actúan en función de estímulos no solamente teatrales sino circunstanciales, no perciben cuándo acaba y cuándo empieza, ni pueden identificar exactamente dónde están los elementos teatrales, etc.

Esto se puede comprender a partir de un concepto de Guattari que se llama "territorialización":

Los seres existentes se organizan según territorios que ellos delimitan y articulan con otros existentes y con flujos cósmicos. El territorio puede ser relativo tanto a un espacio vivido como a un sistema percibido dentro del cual un sujeto se siente 'una cosa'. El territorio es sinónimo de apropiación, de subjetivación fichada sobre sí misma. Él es un conjunto de representaciones las cuales van a desembocar, pragmáticamente, en una serie de comportamientos, inversiones, en tiempos y espacios sociales, culturales, estéticos, cognitivos (Guattari y Rolnik: 323).

Esta concepción teórica contiene otra. El análisis se inicia cuando en el ritual existe una totalidad: las personas que hacen el ritual y las personas que participan en el ritual lo viven conjuntamente, como un hecho único. Y viven como si fuese parte de su vida. De hecho, el ritual forma parte de sus creencias y de su forma de actuar en la vida. Es una parte de ella. Sucede que cuando aparece el teatro en el sentido moderno, entre el siglo XVI y la Ilustración, lo que se produce es una diferenciación que separa a unos y a otros, a los que hacen el teatro y a los que lo observan. Es lo que se llama un proceso de autonomización del arte, y lo que se vive desde ese momento se va a llamar experiencia estética. Estas experiencias estéticas proceden de la introducción, en el corazón de todos estos sucesos, de la ideología burguesa, que se basa fundamentalmente en la producción del sujeto libre y en la proyección en el escenario de la intimidad del sujeto, de sus ideas, de sus emociones, de las cosas que le preocupan, de su manera de hacer el mundo, tanto en un nivel que podríamos llamar privado (por eso Diderot elabora como elemento central del nuevo teatro lo que se llama la escena del "salón de estar") como en lo público. Emociones e inquietudes de un individuo que está integrado en una comunidad (pero que mantiene su individualidad) y que, por tanto, tienen que dar cuenta de su relación con la misma (con lo que se produce la división 
individuo/sociedad). Su relación es normalmente problemática. Tanto el "salón de estar" como esta problemática social constituyen básicamente el grueso del teatro latinoamericano establecido académicamente desde los siglos XIX y XX. No hablamos aquí de estéticas, de géneros o de estilos ${ }^{6}$. Puede haber escenas privadas tratadas de manera realista (como El día que me quieras del venezolano José Ignacio Cabrujas, 1979), y escenas privadas tratadas de modo vanguardista (como Telarañas del argentino Eduardo Pavlovsky, 1977). La diferenciación estética no impide que sigamos hablando de problemáticas típicamente burguesas del individuo, del "sujeto libre". Y entrecomillamos sujeto libre porque esa es la definición que establece la burguesía. Es tal la fuerza de esta matriz productiva que realmente en Europa y en Latinoamérica es la productora de una gran parte del teatro dramático. Es lo que vemos tanto en México, como en Brasil, como en Chile. Esta "homogeneidad" se explicará más adelante cuando abordemos el término latinoamericano. Este proceso de autonomización del teatro supone establecer unos principios y unas normas para el mismo. En realidad, lo que abre es lo que Bourdieu llama un campo artístico que establece un objeto de representación, señalando lo que se puede representar y lo que no (por ejemplo, a partir de este momento todo aquello que no sea el individuo sujeto libre en su intimidad o en su relación social estará prohibido), y unas formas de representación válidas. Estos controles tienen distintas maneras de ejecutarse: desde no financiando las obras a través de ayudas y subvenciones (políticas estatales para el teatro), hasta no dándoles espacios (políticas municipales), pasando por premiarlas o no, y, lo fundamental, estableciendo una serie de características que convierten a las obras en artísticas o no (política académica). La función de todo ello sería legitimar las obras teatrales en el campo, o no reconocerlas y sacarlas del mismo. La conocida afirmación "esta obra de teatro no es arte sino un panfleto", por ejemplo, supone no sólo una calificación sino un modo de presentar la obra como fuera del campo artístico y tratar de bloquearla. Lo mismo sucede con el objeto o el tema de la obra. Ahora bien, como todo lo que se ajusta a ese campo es legitimado entonces se establecen criterios que van a ser los conformadores de la crítica teatral. Los criterios son a veces de carácter ambiguo, como el de "profundidad" o el de gusto, y otras veces de carácter técnico, como el

6 Defino estilo como la manera de expresión, de formar los signos y los enunciados. Rasgos formales. Impresionismo, expresionismo, realismo, etc. El género como la configuración histórica de constantes semióticas y retóricas que coinciden en ciertas obras. Vodevil, tragedia, comedia del arte, etc. y la estética: modo como trabaja la imaginación social, modelo, modo de representación. Registro de identificación. 
de "desarrollo de la trama" o el uso de estilos, sin olvidar los "externos" a la crítica como los morales, económicos, etc. Lo diremos en términos del siglo XIX: una obra si llega al centro del alma humana, de la esencia humana, entonces es legitimada como una obra universal (es decir, válida para cualquier ser humano del mundo); si además resuelve adecuadamente los principios artísticos que rigen ese campo, entonces es legitimada como una buena obra artística (que merece ser estudiada y convertida en referencia, con posibilidades de pasar al canon). Universal y referencial la posibilitan para pasar al canon, lo que no significa sólo ser reconocida con premios, etc. sino que convierte la obra en modelo productivo. Al señalar cómo se deben escribir las obras para que sean reconocidas en el campo, también hace que se escriba para ese campo, y para que sean reconocidas deben reproducir el objeto y los principios que dominan en el campo.

Ahora bien, el campo no está cerrado, no está fijado definitivamente, de hecho, siempre se producen en él crisis. Precisamente porque hay agentes que entran en el campo haciendo obras que cambian el objeto o los principios artísticos, es por lo que se modifica el campo: es el caso del intento en Latinoamérica de normalizar las culturas indígenas dando entrada en el campo al ritual, o de incorporar las acciones y dispositivos escénicos, admitiendo en el campo las teatralidades. Cuando se produce esto, los que entran son considerados en la terminología de Bourdieu como vanguardia, por eso, el término usado en el sentido en que se le da en la historia del teatro es excesivamente limitado. Con la vanguardia no se está pensando aquí en las vanguardias artísticas históricas (surrealismo, dadaísmo,

Egon Wolf escribe una obra que trata de legitimarse en el campo artísticoteatral del Chile de los años sesenta, pero también de la sociedad burguesa. Esto supone que los límites de transgresión están sublimados (es un empresario, no el empresariado, son los pobres, no el proletariado) y no son directos, lo que le permite hablar de tú a tú a la burguesía y no hacerlo desde una posición marxista. expresionismo, etc.), sino que se considera las obras que traen un objeto nuevo, unas técnicas nuevas y unos principios estéticos nuevos, o modificaciones fuertes de los existentes. Desde esta perspectiva, "vanguardia" señalaría una posición, unos recursos y un capital que se lleva al campo artístico en un momento dado de su estado, y no un discurso escénico. En el campo hay agentes que sostienen la hegemonía legitimando su objeto y sus principios. Solamente cuando esa vanguardia cuenta con fuerza suficiente entonces es posible modificar el campo. Si se modifica el campo, los que lo dominaban están obligados a hacer nuevos movimientos para volver a controlarlo (la mayor parte de las veces mediante la asimilación o la recuperación); por eso podemos decir que el campo cambia. Y eso es lo que sucede cuando 
en momentos en los que la problemática social conmociona todos los ámbitos de la sociedad. Entonces, el campo se ve sacudido por una crisis (de legitimación, de discurso, etc.), cuando los que entran en el campo intentan plantear un objeto nuevo: por ejemplo, lo que le pasó al teatro político intentando introducir su nuevo objeto, el poder. Para ello ponen en juego una analítica de esas relaciones de poder. Cuando ese intento se produce en un tiempo de conflicto social en que se cuestionan las estructuras sociales, es muy difícil que el campo prohíba ese tipo de proyectos. Normalmente lo que hace entonces es tratar de empobrecerlo imitándolo, pero eliminando la analítica del poder que es el discurso teatral que produce, lo mismo que hizo con el ritual.

Otro aspecto importante cuando tratamos de hacer una catalogación del Teatro Crítico Latinoamericano es comprender que dentro del ámbito que hemos llamado teatro hay numerosas diferencias (estéticas, genéricas, etc.); algunas distinciones, sin embargo, carecen de fundamento. Por ejemplo, no existe (aunque muy a menudo se hace esta distinción) un tipo de teatro que pueda definirse como teatro comercial, pues si bien puede hablarse de un teatro para el que sólo cuenta el valor económico (lo que ingresa) o el éxito (el público que atrae), de hecho, si tiene éxito económico y de público sólo indicaría que reproduce el gusto social, el dominio ideológico de la sociedad en la que se da. Por tanto, ni los teatros denominados marginales, ni los teatros llamados comerciales tendrían que distinguirse excepto en si configuran o no un discurso crítico. Así, si se quiere, habrá teatro crítico marginal y teatro crítico comercial. Este es el teatro que tendría que documentarse.

A la vista de esto, sería necesario que hubiese una documentación de los espectáculos, de los textos (véase Apéndice 1). De la misma manera que todas las sociedades burguesas han edificado sus bibliotecas, sus archivos, y lo tienen porque construyen su historia a partir de demostraciones, también debe construirse un archivo del Teatro Crítico Latinoamericano en el que tengamos un conjunto de textos, temas, proposiciones ideológicas, formas artísticas, etc. de carácter crítico, y que nos pueden servir para conocer aquello que no es noticia en los periódicos, ni materia de discusión política, ni se estudia en las academias, etc. Este archivo alternativo nos permitiría, además, saber cómo se representó, qué intenciones tenía, que dispositivos puso en juego, para así poder conformar otra historia de Latinoamérica, como 
enseñó Eduardo Galeano en su Memoria del fuego. Una historia propia de Teatro Crítico Latinoamericano. Cuando leemos historias del teatro argentino, o brasileño, encontramos, primero, el modelo nacional de la burguesía, y, segundo, todo aparece sometido a los mismos criterios estéticos, a pesar de que pueda haber capítulos sobre "teatro militante", "teatro social", etc. que ya demuestran un intento de relegarlos a un segundo plano o de dar una interpretación circunstancial. En estas historias de nombres, de épocas, de títulos, no vemos nada sobre lo que necesitamos saber: cómo se han construido, a qué hacen referencia, etc., por más que haya tratamientos y temas que no encuentran equivalente en el teatro comercial.

\section{¿Dónde se produce el teatro?}

Necesitamos dar cuenta de cuatro o cinco conceptos importantes para nuestro tema que tienen que ver con lo que podríamos llamar la constitución de la sociedad. Tratamos con ello de establecer la compleja red de articulaciones que producen una obra teatral. Tendríamos en primer lugar la(s) cultura(s), que incluyen la ciencia, la ideología, la moral. En principio podríamos definir la cultura como la producción de fenómenos que contribuyen

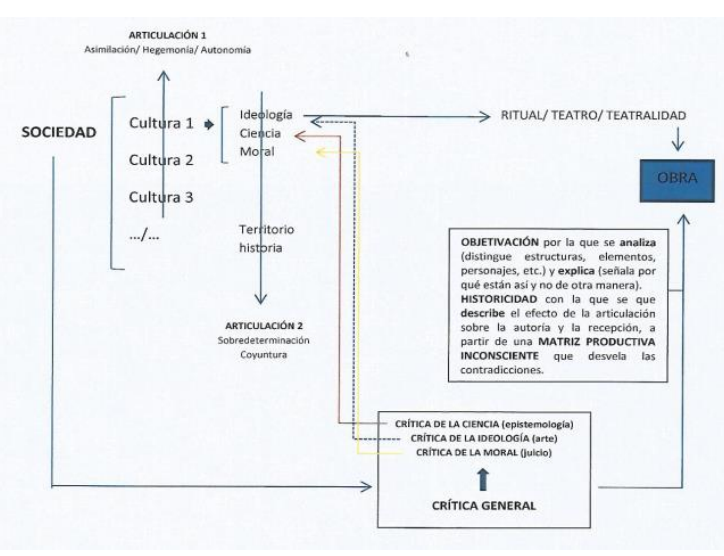
a la reproducción de la sociedad y que, según los diferentes estadios de complejidad de la misma, ha dado un conocimiento de la misma (mediante la ciencia), una representación de la misma con el que establecer un sentido (mediante la ideología) y una valoración de dichos fenómenos (mediante la moral). La cultura es un medio que pasa inadvertido para nosotros, que consideramos "natural" mientras sólo lo estemos viviendo. Es como el ejemplo de Marx de que "la atmósfera en la que vivimos ejerce sobre cada uno de nosotros una presión de 20.000 libras y, sin embargo, no la sentimos". Solamente un trabajo reflexivo (el impulso inicial de la crítica) nos permite comprenderla. La cultura podría definirse, pues, como un proceso de producción y reproducción de la vida social. Diariamente reproducimos nuestras formas de vivir y un ejemplo de ello sería la tradición. No es cuestionada, no se establecen críticas sobre ella, pasa como si fuera nuestra constitución social extendida en el tiempo. Se producen, naturalmente, desfases, problemas, contradicciones, y es por eso por lo que 
siempre hay conflictos y por lo que nunca se reproduce de manera exacta y sin transformación.

Así pues, en una sociedad puede haber muchas culturas (como en Chile, en México, etc.), pero también hay diferentes clases sociales que han establecido culturas diferentes: tenemos una cultura nacional, una cultura local, una cultura patriarcal, una cultura imperial, una cultura obrera, etc.

Un mecanismo propio de la dinámica cultural es cuando la sociedad hace un proceso de objetivación de esa misma cultura, cuando trata de pensarse fuera de esa cultura, cuando trata de analizarse desde otro lugar, entonces se está poniendo en funcionamiento un discurso científico. Es la propia cultura la que lo hace, por eso la ciencia está en el dibujo 2 dentro de la cultura, porque también ella está sometida a todas esas instancias de producción y reproducción cultural (y por eso Althusser pensó que la filosofía servía como una manera de desligar ciencia e ideología). Los conflictos en la sociedad, consecuentemente los conflictos en la(s) cultura(s), pueden producir conflictos en las ciencias. Si no fuera así no podría entenderse por qué la ciencia cambia. Lo mismo sucede en el nivel ideológico: la sociedad se compone también de procesos de producción de fenómenos que contribuyen (en arte mediante la representación o construcción simbólica) a reproducir el sentido fijado provisionalmente o a transformar el sistema social, lo que sería una práctica de sentido. Por ejemplo, tenemos en una cultura un ritual que no conocemos y del que sólo vemos formalmente los movimientos y los gestos de las personas que participan en él. Podemos describir ese elemento cultural de esa sociedad, pero no podemos comprenderlo porque carece de sentido para nosotros. Para ello tendríamos que hacer un análisis ideológico, entendiendo por ideológico no el conjunto de ideas o saberes, ni el concepto marxista de falsa relación de las personas con sus condiciones de vida, sino de la lógica que articula los significados sociales. Y, en tercer lugar, tendríamos lo que definimos como producción del valor social. Este ritual que hemos dicho que para la ciencia puede ser objetivado a través de la antropología, por ejemplo, y que produce sentido, puesto que para esa cultura es necesario como forma, por ejemplo, de fertilizar la tierra, va ligado al hecho de que esa esa comunidad produce juicios en torno al cuidado de esa tierra, al valor que tiene para los individuos que 
constituyen esa comunidad, tiene un valor social, tiene que ser reconocida socialmente, y eso lo establece la moral, es decir, las conductas que deben funcionar en torno a este ritual: por ejemplo, el tabú, el tabú es una prohibición del valor social de algo (el incesto en muchas culturas). La moral funciona como código del valor social de las cosas, a las que se le atribuye el valor de bueno o malo, caduco o vigente, etc. Como se muestra en el dibujo 3, el resultado del cruce de estos espacios culturales es un punto central que es una zona de confluencia: estos círculos tienen cierta autonomía unos de otros pero que también se interrelacionan haciendo que estén en constante tensión. Así un análisis científico puede estar lastrado por una idea de orden moral-ideológico (así le ocurre a Galileo, y esta confluencia de espacios es lo que representa Brecht en la escena teatral). Este punto es un punto de fijación provisional de la sociedad. ¿Por qué es provisional? Porque la tensiones en todos los niveles
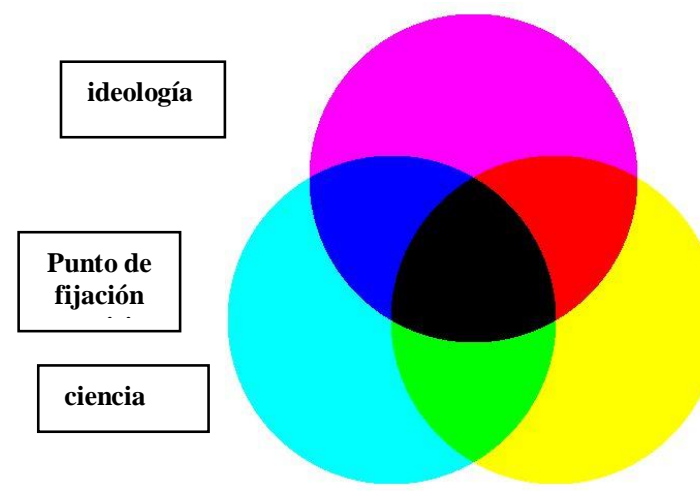
de la cultura, de la sociedad, hacen que siempre haya desplazamientos, que se muevan los territorios y los límites, y solamente cuando hacemos una fotografía (que fija esos movimientos) podemos decir la sociedad es esto. Pero siempre es una fotografía que muestra algo pasado ya.

Cuando las culturas se encuentran pueden ocurrir varias cosas: uno, que una cultura asimila a otra. A través de los rasgos comunes una cultura puede ir definiéndose o redefiniéndose en la otra. $\mathrm{O}$ fundirse, una en la otra y la otra en la una, en un proceso de hibridación. Es lo que ha sucedido con buena parte de las culturas en Latinoamérica. También puede darse un proceso de hegemonía cultura por la que una interviene a la otra: por ejemplo, mediante un dominio político (la interviene políticamente), eliminando o prohibiendo, por ejemplo, los rasgos que son negativos para su control. Sucede lo mismo cuando se instalan en una cultura

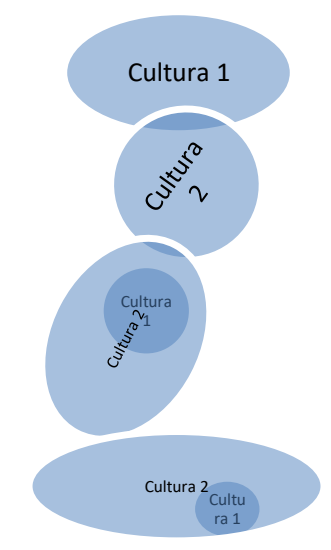
elementos de otra (la dominante) pero que tienen más potencia que los de la primera: por ejemplo, si una cultura trata de imponer, frente al don, el intercambio monetario, puede conseguirlo si ese modo de intercambio monetario es dominante en buena parte del mundo y resulta necesario para desarrollar las actividades de un gran número de sociedades (potencia). Ese rasgo puede ir corrompiendo la economía del don. Se produce así hegemonía sin 
necesidad de la violencia, sin necesidad de control. Se dominan los horizontes de esa cultura. También por la moral, introduciendo valores dentro de la otra cultura que resulten problemáticos en función de cómo los viven en otras sociedades. Esto es el asunto del relativismo cultural: hay rasgos de una cultura que para otra son inmorales, pero su intervención política hace que se produzca un hecho de dominación cultural. El conflicto intercultural abre el problema de qué tipo de reflexión hace la crítica respecto al teatro: si una obra mapuche, por ejemplo, muestra una visión del tiempo cíclico, en lugar del racionalista tiempo lineal; o un ritual Tarahumara, expresa la comunicación con Dios, ¿la crítica debe considerar estas visiones y creencias como sin sentido? Aquí conviene tener claro que una respuesta afirmativa sería un caso claro de cómo una ideología explota en su beneficio a la ciencia, de la misma manera que caracterizar a este teatro como "primitivo" en aras de un supuesto progreso del hecho teatral sería un caso similar de explotación de la ciencia por una ideología. Eso no es materia de la crítica. Un teatro crítico no tendría que mostrar el punto fijo con el que se suele definir a una sociedad. Un discurso crítico, un teatro crítico, tendría que intentar mostrar el punto en movimiento, por eso es dialéctico, por eso trata de poner en la escena cosas que están en discusión en ese momento, en contradicción en ese momento. El argentino Carlos Gorzostiza, en El pan de la locura (1958), desarrolla un drama de envenenamiento de semillas sin que podamos conocer la estructura del hecho al mantenerse en un nivel costumbrista. 


\section{Lo que es y lo que no es crítica}

Existe una idea general de crítica (la llamaré noción) que la define como un trabajo de análisis textual, escénico, de una obra. Sin embargo, el concepto $^{7}$ de crítica sobrepasa esa noción para situarse en el análisis de la matriz productiva desde la que se ha generado la obra. Esta matriz es radicalmente histórica, es decir, está determinada por las condiciones materiales que derivan de la articulación precisa y coyuntural de las estructuras que constituyen los niveles de la sociedad; y radicalmente materialista, esto es, está determinada por las condiciones ideológicas que relacionan los discursos y las condiciones reales de existencia de los individuos que participan de ese sistema social. Pongamos un ejemplo: acabo de terminar una obra sobre
Los invasores muestran ese punto de fijación social en movimiento, inestable, utilizando un recurso teatral sencillo: después de asistir a los hechos derivados de la invasión de la casa de los Meyer, que vivimos como en tiempo presente, escuchamos las voces que proceden del dormitorio del matrimonio y el comentario de Pietá: "Despierta, hombre. Descansa. Has tenido una pesadilla" (80). Lo sucedido no pasó. Ahora volvemos realmente al presente y dejamos la pesadilla, que se ha convertido en pasado. Más importante aún: no ha ocurrido. Sin embargo, cuando se reúne inmediatamente después con sus hijos y les cuenta a ellos algo de lo que ha soñado, Bobby, entonces, le dice que eso ocurrió "ayer". El juego de los tiempos hace que el relato, pasado ya, pero presente antes (durante casi toda la obra), anuncie el futuro. De esta manera también en la obra es imposible fijar definitivamente qué está sucediendo, y nos señala una sociedad movediza y cambiante. También aparece en la actitud del matrimonio: todas las afirmaciones que marcarían un punto de fijación estable, como la solidez de la que hablan al comienzo de la obra respecto a su posición social, el hecho de que él no haya tenido "nunca una duda, nunca un fracaso", están atravesadas por sensaciones y síntomas que Pietá observa entre su propia clase social: ella se pregunta si es sólida esa situación del matrimonio, por sus vértigos, sus supersticiones, su miedo. Desde el primer momento el espectador ve representarse un mundo mudable.

una población. Más concretamente sobre la olla común. He representado esa tarea comunitaria que era intentar encontrar alimentos para la población, una forma de convivir, una red solidaria, etc. Ha terminado la obra y ahora se me hará una "crítica". En realidad, esta noción no es el concepto crítico que se propone aquí. Esta noción esconde sólo un juicio artístico (moral) sobre si es buena o mala la obra; un juicio ideológico (académico) sobre si es aceptable estéticamente la obra o no, etc. Se pide saber cómo estuvieron los actores, si lo que contaba la obra era nuevo o algo ya conocido, sobre la escenografía, sobre si era emocionante, etc. En realidad, con esa noción estamos en el terreno de un comentario valorativo. Lo que se representa y si responde a la realidad del momento histórico. Lo que quiso decir la compañía. Más allá entramos en la mecánica: hablar de los procedimientos estilísticos que la han producido, ver las operaciones y procedimientos que la construyen, poder entenderla para valorar su significación. Hasta aquí la noción. El concepto se forma en varios momentos de un largo proceso. El primero, ya en nuestra época moderna, que se desarrolla entre los siglos XV y XVI, se caracteriza porque se introduce un discurso de interpretación en la lectura de los textos canónicos, de los textos sagrados, por ejemplo, de

\footnotetext{
${ }^{7}$ La diferencia entre una noción, un conocimiento elemental, sin conexiones con otros elementos; y concepto, un conocimiento integral, que está en relación estructural con otros elementos, sirve para señalar la complejidad de elaboración del discurso crítico frente a otros discursos denominados así y que, desde una perspectiva teórica exigente, no lo son.
} 
$\overline{\text { la Biblia. La Biblia era la palabra de Dios y, por tanto, no era interpretable sino transmisible }}$

solamente por aquellas personas que estaban designadas por él mismo para hablar en su nombre. Consiguientemente, toda interpretación era herejía. Bien, cuando existe una interpretación distinta a la de los sacerdotes entonces se entiende que se produce una ruptura, esa ruptura se llama crítica porque para producir esa interpretación se requiere comprender la obra en cuanto estructuras de significación en relación con las condiciones sociales: la obra dice esto porque compone así sus signos, sus enunciados, sus proposiciones, etc. y esto que dice funciona para la reproducción o producción de la sociedad. Naturalmente, esta interpretación es susceptible a su vez de ser criticada. En el segundo, se da un paso mayor. Estaríamos en Kant (siglo XVIII), y para Kant la crítica es el discurso que da cuenta de los mecanismos que el ser humano usa para comprender el mundo. Hasta ahora lo habíamos comprendido directamente (sentido común) o a través de los mitos, pero en realidad hacemos un montón de operaciones en la cabeza para tratar de comprender el mundo de otra manera. Todo ese conjunto de operaciones que trata de separar lo mitológico de lo racional (el operador racional) es lo que llama se llama entonces crítica. Considera que el discurso mitológico o religioso oscurecen el mundo, no lo iluminan (el sistema de la Ilustración te interpela "atrévete a saber"). Si en el primer momento se señala un trabajo desde el texto, con trabajo sobre el propio mecanismo de pensar. Ahora bien, este mecanismo es racional y parece ser descrito como un operador ideal, hasta el extremo de afirmar que las condiciones 
del conocimiento las da el sujeto que conoce y no el objeto. En el siglo XIX hay una nueva concepción de la crítica, que procede del trabajo de Marx y Engels fundamentalmente, y que dice que esos procesos de conocimiento no los hacen los individuos en su condición de científicos, intelectuales, etc. sino como miembros de una determinada clase social, y que tales discursos están determinados por condiciones históricas y sociales precisas. Entonces, introduce sobre el mismo hecho, el intento de comprender los mecanismos de conocimiento del mundo, una variante radical: que esos mecanismos de interpretación que Kant sitúa en el ser humano no proceden de esa idea universal de ser humano, sino del conjunto de condiciones históricas y materiales en la que los seres humanos viven. Se ve bien que incorporamos lo histórico al concepto de crítica. Finalmente, existe en los años sesenta y setenta del siglo $\mathrm{XX}$, una crítica a la misma raíz del discurso crítico para devolverla a la cultura. Se trata de una crítica que se reconoce situada, y que renuncia a validar un discurso crítico universal para señalar la existencia de una razón colonial que llama la atención sobre el hecho de que esos mecanismos materialistas que proceden de condiciones históricas, también proceden de condiciones de poder, pues esas condiciones han dado lugar a una epistemología concreta que denominan colonial y que realmente habría que introducir nuevos mecanismos internos a la crítica que reconozcan la imposibilidad de la crítica de situarse fuera del dominio cultural. Sustancialmente aquí es donde estamos.

Así pues, la crítica actúa en el interior de una cultura, de una sociedad, pero también debe reconocerse que, igual que hay relatos utópicos (que hablan de un "sin lugar"), los procesos que se dan en el interior de esa cultura, de esa sociedad, como los excedentes, las contradicciones, los callejones sin salida, producen un paso más allá de lo que había, del marco instituido socialmente. Pues bien, este paso más allá de lo que había es el resultado de la operación crítica. Más allá de lo que había significa no ir más allá del texto, pero tampoco quedarse más acá. Significa encontrar lo que el texto no ha dicho explícitamente, es decir, no analizar su enunciación, lo que dice, sino lo que dice implícitamente, el discurso que se liga a la matriz productiva, y con categorías que no reproducen el mismo, sino que lo explican en su constitución total (desde el sujeto que lo produce hasta el sujeto que lo interpreta). Un ejemplo sencillo: si alguien pregunta a un grupo de gente qué trabajo quieren de entre estos: fregar escaleras, pasar textos al computador, o hacer comentarios deportivos en un periódico, 
alguien podría analizar las tres propuestas en su contenido explícito y valorarlas, pero un discurso crítico empezaría por advertir que la pregunta está formulada partiendo del hecho de que debe haber un trabajo (y no tareas decididas colectivamente), y de que debe realizarse uno y no otro (no contempla el carácter rotativo), y que debe ser salarial (y no considerar una renta básica). También que tal pregunta puede aparecer porque el salario y su posición de sujeto "libre" para ser contratado (es decir, carente de los medios de producción) convierten al individuo de trabajador en proletario. ¿Cómo lo he hecho?: a) desarticulando la pregunta; b) llevándola a un lugar anterior a la de su realización. Así funciona un teatro crítico: no pone en escena unos hechos, sino que al ponerlos también tiene que mostrar los procesos que han dado lugar a que sean así y no de ninguna otra manera. En la obra del dramaturgo uruguayo Andrés Castillo La bahía (1960) se relata un suceso en la vida de un grupo de marginados que viven en una zona del puerto de Montevideo. Su pobreza, sus “destinos” sin horizontes, su violencia es mostrada con crudeza. Podríamos decir que es una obra crítica porque nos dibuja una situación intolerable, pero eso sólo la haría una obra moral. Podríamos decir que lo es porque los reproduce bien, en relación con la realidad social de ese tiempo, pero entonces sólo tendríamos una valoración estilística: es una obra realista; podríamos decir que nos enseña algo que no conocemos del mundo, un hecho social, pero no nos dice lo que el teatro crítico trata de mostrar: el origen, de dónde procede esa pobreza, de dónde esa violencia, cómo se mantiene, etc. Aun sin ser el tema que quiere expresar, el discurso crítico podría haber sobrepasado la anécdota. Todas estas cosas hubieran convertido esta obra social en una obra crítica. Esto, en realidad, nos lleva a otro problema del que depende la elaboración del corpus de textos escénicos que se incluirían bajo la denominación de críticos: obras sobre la tortura, como la argentina El asesinato de $X$ (1970) de Libre Teatro Libre, o la chilena La muerte y la doncella de Ariel Dorfman (1990), pueden ser críticas en un tiempo histórico concreto (el tiempo de la dictadura y la transición), en tanto que

...... El análisis de la coyuntura nos permite entender que en el problema habitacional, de miseria y marginalidad que lleva consigo, está el centro de un conflicto estructural, que interpela a toda la sociedad: a las ideologías burguesías, representadas por el gobierno de Jorge Alessandri, promotor de un ambicioso, reformista e insuficiente Plan habitacional (que se propone para bloquear el conflicto), a las ideologías democristianas, que declaran saber que la revolución cambia las estructuras de la sociedad y, por ello, tienen que asumir el discurso de las jerarquías eclesiásticas y las bases cristianas para frenar la revolución "cristianizándola", llevándola por canales humanos y <despojarla de venganza, de resentimiento, de ambición, de lucro, de violencia, de injusticia” (Garcés: 246) (¿no es eso lo que dice China?), como señalará la revista Mensaje en 1962; a las ideologías socialistas y comunistas (Frente de Acción Popular, Partido Comunista), que tratan de sobrepasar a los gobiernos burgueses apoyando estas tomas. Esta distribución de posiciones ideológicas se refleja en la elaboración de los personajes: en el ámbito de las clases altas, Pietá, la representación democristiana, tal y como aparecer en la pastoral El deber social y político en la hora presente (1962), y Meyer, la representación burguesa; en el ámbito de las clases populares, China y su grupo, representantes de todas las posiciones políticas de la izquierda (incluida la cristiana). En la cuestión poblacional se encierra otra que caracteriza la coyuntura. El problema de los Meyer (“¿qué hace dentro de mi casa?", dice Meyer a China en su primer encuentro, o Pietá reclamando que no le quiten sus joyas), es el conflicto político del Chile de ese momento: la propiedad privada (cf. Juan Carlos Gómez en "Democracia $\mathrm{v} / \mathrm{s}$ propiedad privada"). Es lo que expresa un exaltado Bobby: "El ocaso de la propiedad privada". Para este historiador la coyuntura esta, además definida, por la crisis del Estado Capitalista de Compromiso (Gómez: 40 y ss.). descubren y denuncian algo oculto y terrible, pero que en un contexto democrático quedan 
de alguna manera desactivadas, o pasan a formar parte de la ideología humanista. Nada es puro. Todo está amalgamado, por eso la crítica es una intervención analítica sobre el texto, sobre la escena, esto es, un trabajo de separación de los elementos que la componen y funcionan en la obra, para llegar a conocer sus principios, sus formas de articulación, y sus determinantes histórico-ideológicos.

Tratemos de entender el lugar de la crítica en nuestras sociedades. Pongamos que viajo por carretera a Iquique y que no hay señalizaciones: en algún momento puedo estar dando vueltas en el mismo círculo sin llegar nunca a Iquique. Pongamos que alguien pone señalizaciones: si pone señalizaciones y creo en ellas, porque se supone que están objetivadas y se han hecho siguiendo unos criterios de distancia, etc. esas señalizaciones pueden ser falsas porque nos llevan por los caminos que considera (vemos pues lo que quiere que veamos) y hace que dure el viaje el tiempo que quiera. Ahí se impondría hacer un nuevo mapa, recorrer el camino y hacer un itinerario diferente, con criterios distintos (como hizo, por ejemplo, Arno Peters al hacer el mapa del mundo a partir de una nueva proyección). Esta es labor de la crítica, volver a recorrer el camino de la obra y hacer las marcas oportunas para decir qué hay en la obra que no dice. También puede suceder que en ese viaje alguien pueda decir: a usted le queda mucho, o es un feo paisaje. Igualmente puede señalar "el viaje que usted lleva a Iquique es el de su destino". En estos tres casos últimos lo que estaríamos diciendo es que hay una valoración de ese viaje físico, artístico, emotivo. Pero el nuevo mapa no contempla este sentido, sino otro.

Las teorías poscoloniales y la Teoría Crítica nos llaman la atención sobre eso que se llama razón, que es propia del ser humano pero que, al final, de esa humanidad abstracta no tiene nada, sino que es pura materialidad. Esta crítica de la razón la definiría como un operador lógico, que quiere decir que realiza operaciones entre argumentos, ideas, etc. realiza pues operaciones (pone en relación dos ideas para hacer algo con ellas), pero además dice qué es lógico, lo que significa que se atiene a principios formales y relaciones, y que, derivado de los mismos, da cuenta de un conocimiento. Cómo son estos principios: la filosofía clásica estableció varios: uno, el abductivo: a partir de la descripción de un hecho se llega a una hipótesis que la explica, pero tal hipótesis es inestable: es probable pero no segura. 
Deductivo: a partir de unos principios a priori que yo presento veo la realidad y establezco los hechos. Inductivo: a partir de las observaciones sobre la realidad yo establezco una ley, una teoría.

A partir de esto se puede decir que la razón no es universal, destripada, abierta en su interior, sino resultado de un tiempo histórico y de un sistema social. En la caja de la razón no hay nada. Es sólo un mecanismo. Lo que se utiliza como razón instrumental, como razón imperial es eso: un uso instrumental de las cosas y de las personas, un uso imperial, de explotación y dominio, de las cosas y de las personas. El elemento razón está vacío y se rellena de los otros elementos que son históricos y sociales. Por eso, cuando alguien recrimina a otro "usted no es razonable, eso que dice no es razonable" en realidad no está diciendo nada. Tendría que decir, no es razonable según la razón imperial, según la de mi clase social, según la razón instrumental, etc.

Exactamente podemos exigirle lo mismo a una obra de teatro: cómo razonan los personajes, cómo razona su estructura: qué elementos articula y cómo, para decir qué. Y así, podemos afirmar que esta crítica va primero contra el sentido común puesto que éste es el sentido instituido (que reproduce el sentido dominante), y común en tanto que está en esa cultura, fijado provisionalmente, y que se transmite. Por el contrario, vemos que el discurso crítico no es común, sino que está ideologizado (atravesado por relaciones de sentido), politizado (atravesado por relaciones de poder). Además de contra el sentido común, la crítica está en contra de la opinión porque lo único que diría es que este sujeto libre (que, ya hemos dicho, que no lo es puesto que la burguesía lo considera así después de desligarlo de sus determinaciones históricas y sociales), estaría elaborando una idea "personal" de esa obra, pero la opinión siempre procedería de una arbitrariedad inaceptable para el discurso crítico que lo considera fruto de la ideología dominante.

La teoría crítica que estamos esbozando nos obliga a ir a la matriz productiva: esa obra tiene que mostrar la matriz de origen (que hemos dicho que es burguesa), la matriz ideológica de la que nacen sus relaciones, no discutir si los pobres en las obras de Castillo están bien representados, que es el campo de juego que nos da la burguesía, sino la significación de esa 
pobreza en relación con la matriz ideológica inconsciente que la sostiene. Un ejemplo significativo: en una escena de Nuestra América (2013), obra de la compañía chilena Teatro Público, se afirma el expolio y explotación de América y se desvela cómo ese expolio produce la modernidad europea. Eso es establecer argumentos críticos contra la idea del proceso de civilización y la idea del "esfuerzo de los conquistadores", de lo que hicieron en América los conquistadores. Comparado con la obra del colombiano Enrique Buenaventura Un réquiem por el padre de las Casas (1963), que es un homenaje al clérigo sevillano por su defensa de los indígenas americanos, Nuestra América no abandona lo sustancial: que la maquinaria de la esclavitud no es un problema sólo moral sino, fundamentalmente, de explotación y enriquecimiento de Europa; que el ejemplo moral de las Casas (del que se elimina en la obra su aceptación de otras esclavitudes y explotaciones) no explica las razones estructurales de un tipo de relación de poder como la que se dio en América. Esto es un problema para el teatro crítico: leída en su totalidad, la obra de Buenaventura, si bien inicia la discusión con el discurso imperial (y en este sentido se puede pensar que ya hay una labor crítica), acaba reafirmando otros sentidos: que entre los soldados, clérigos y diplomáticos que llegaron a América había gente buena. De nuevo, el discurso crítico es explotado por el moral.

La complejidad de este desarrollo materialista de la crítica fue tal que el propio Marx tuvo que hablar de crítica de la crítica. Es importante, entonces, tratar de definir ese inconsciente ideológico, aquel en el que se inscriben las relaciones sociales y los horizontes de sentido invisibles que nos construyen como sujetos o construyen los hechos sociales y de las que sólo tenemos huellas o síntomas, cómo determinan el texto teatral esas relaciones sociales y horizontes de sentido, y en qué forma estilística, sígnica, discursiva se materializan. Este sería el punto máximo de desarrollo crítico.

Aparecen, desde otras perspectivas, varios problemas más a la hora de realizar la crítica: uno, aceptamos la autonomía de la obra o la consideramos dependiente. Esto tiene consecuencias: ¿considero la obra en función de si reproduce adecuadamente el objeto que representa? ¿No es esto, en realidad, un problema estético? Los debates sobre vanguardia y realismo son habituales en el teatro latinoamericano. Se acusa a la vanguardia de deformar la realidad, 
pero la vanguardia reclama la autonomía, la libertad de la creación. Y, sin embargo, esto no es un problema para la crítica puesto que, como muestra Bourdieu, la existencia de un campo y su funcionamiento "autónomo" no niega que ese campo se ha formado en contexto histórico y social. Los discursos sobre la autonomía defienden que la obra teatral debe ser analizada a partir de las reglas que la obra se da a sí misma, pero para la teoría crítica esas reglas están segregadas por una matriz productiva de carácter histórico y social. Igualmente sucede con el estatuto de ficción: el problema no sería aquí la ficción sino la ilusión que muchas obras buscan. Esta crítica tendría que atender a lo implícito y a lo explícito. A lo dicho y a lo no dicho: hay muchas obras que tratan de presentar un fresco que muestre la totalidad de lo que suponen las dictaduras, y lo representan en varios fragmentos (como El asesinato de X), el problema es que dejan sin decir las cadenas que hacen que esos hechos marcan a toda la sociedad, la orientan. Debe atender también a la profundidad y a la complejidad: una cosa en intentar llegar al máximo expresivo y al máximo contenido de una situación, cuántos elementos intervienen, de qué manera lo hacen, y otra es la complejidad que analiza qué relación guardan esos hechos con respecto al resto de elementos que podrían aparecer ahí. Como se puede ver la crítica es un discurso inagotable y, por ello, sólo es productivo cuando se trata de comprender o conocer un hecho concreto.

\section{Una definición aproximada}

Crítica no es una opinión, ni un comentario, ni una valoración, ni una distinción (criterios). Es un procedimiento de objetivación (procedimientos científicos) de la obra o la realización escénica, que analiza y explica históricamente (coyuntura y punto de fijación social) mediante un análisis de las sobredeterminaciones ${ }^{8}$ (y no sólo de las determinaciones) tal obra

\footnotetext{
${ }^{8}$ El concepto de sobredeterminación en Althusser La revolución teórica de Marx, México D. F., Siglo XXI, 1988. Una sintética y magistral explicación puede encontrarse en Carlos Pereyra: "Inversión y sobredeterminación" en Filosofía, historia y política, México D.F., 2010, págs. 117-125 en donde se dice que "Se puede ir más lejos y afirmar que si cada coyuntura histórica constituye un caso único e irrepetible, ello se debe precisamente a la sobredeterminación. Las instancias y elementos en juego, las contradicciones existentes son. en general, las mismas para todas las formaciones sociales que viven bajo la dominación del mismo modo de producción. Si, a pesar de esto, la historia específica de cada país muestra diferencias tan evidentes, la razón hay que buscarla justamente en la singularidad irreductible de la sobredeterminación. Cada uno de los elementos o instancias presentes en una sociedad, considerado por separado, es decir, abstractamente, puede incluso aparecer como semejante a los elementos e instancias de otros países, pero ello no impide que su eficacia sea enteramente distinta según las modalidades específicas de su articulación, según las formas varias de su sobredeterminación. Lo que hasta aquí hemos presentado puede resumirse de modo esquemático en lo siguiente: la dialéctica marxista supone no la idea de una contradicción simple sino de la contradicción sobredeterminada.
} 
o realización escénica, dando cuenta del conjunto de razones (operador lógico que relaciona argumento, los articula y nos da un saber) que ejerce una matriz ideológica inconsciente (lo hace pero no lo sabe) y sus contradicciones para producir un sentido. La obra, según esta posición, no podría haber sido de otra manera. Para ello tiene en cuenta la estructura, la temática (lo dicho y lo no dicho), la forma (que no es la manera en que aparece, su aspecto), sino el contenido), la experiencia (estructura de sentimientos, idea, etc.) ideológico solidificado. También el campo artístico en el que se inserta: la posición en el campo (vanguardia o no), la ruptura de normas y principios de construcción, los aparatos de legitimación, etc. Se trata de un discurso materialista por lo que no concibe condiciones precedentes, sino que se construye a partir de los hechos y de su puesta en cuestión.

\section{La última determinación}

Pasamos al tercer término del título, latinoamericano, y vemos que aparece con él ya otro problema a la hora de caracterizar el corpus de obras que confirmarían el carácter crítico que hemos visto.

Lo latinoamericano tiene un elemento común en todos los territorios que no deriva de ninguna identidad colectiva, sino del hecho de que su desarrollo va paralelo al de las colonias (y no sólo de que haya habido colonización). Esto no ha sido así en otros territorios. Por ejemplo, no se suele hablar de "teatro africano" (y en África también hubo colonización). En África el ritual se mantiene con más fuerza que el teatro, y tampoco ha habido traslado al campo cultural de los pueblos africanos de la cultura europea. Probablemente tenga mucho que ver en eso un diferente "uso" del esclavismo y de las políticas de mestizaje prácticamente inexistentes aquí. Desde el siglo XVIII y XIX, todas las repúblicas que se van independizando adoptan las estructuras de clase de las metrópolis y, consecuentemente, no sólo las estructuras políticas y económicas, sino también las ideologías (los sentidos), sus formas de producir arte, teatro, literatura. Y eso permite ver una similitud en todo el territorio latinoamericano de formas, estilos, etc. Así que pueblos separados y muy dispares, que tenían

Esto explica que, a diferencia de la dialéctica hegeliana, la marxista si haya intervenido en la configuración de la ciencia de la historia. Pero, cabe preguntar, ¿en qué se funda el concepto de contradicción sobredeterminada? La respuesta a este interrogante es decisiva porque no se trata sólo de defender una idea de contradicción frente a otra, sino de evitar que el concepto de sobredeterminación permanezca en un nivel puramente descriptivo". 
culturas radicalmente distintas, con grandes diferencias territoriales e históricas, están anudados en una historia común con Europa. Esto hace, en el caso del teatro, que cuando se preparan antologías, por ejemplo, los textos seleccionados podrían pasar por europeos. En qué se diferencia: en los lenguajes locales, en las anécdotas, y en poco más. Así, géneros como el sainete, que es un tipo de construcción escénica y retórica, tiene su traducción en el sainete criollo en Latinoamérica. Cuando hablamos de la conformación del drama social también podemos decir que procede, en buena medida, de las estructuras melodramáticas de estos territorios comunes. El trasiego de actores, técnicos, entre Europa y América, es constante a lo largo de siglo y medio. Trasladado de materiales textuales, lo que explica que un grupo mexicano represente un texto tan localista como el de García Lorca, Bodas de sangre, y suponga para el público mexicano una muestra de la fuerza telúrica que existe en su cultura. Las diferencias, en buena medida, han sido superadas por una estructura sustancial común. Sin embargo, igual que el teatro crítico propiamente latinoamericano es difícil de encontrar en Latinoamérica, exceptuando al salido de esa estructura sustancial común, sí encuentra posibilidades a partir de la filosofía de la liberación, que intentó poner en el centro del debate cultural si existía algo así como una latinoamericanidad. No se trata de definir una esencia sino, todo lo contrario, una especificidad histórico-social como es la colonialidad. Sabemos que Latinoamérica ha incorporado una serie de elementos críticos que no había en las filosofías de las metrópolis y, sin embargo, por la especie de opresión que produce el modelo europeo no ha podido desarrollarlo en el teatro. Hay notables ejemplos: la pedagogía liberadora de Freire ha dado lugar a un tipo de teatro específico latinoamericano que se ha formalizado en el teatro del oprimido del brasileño Augusto Boal. Lo fundamental de este teatro no es sólo que sea un teatro en favor de los oprimidos (introduce discursivamente la condición del otro, que era básico en la filosofía de la liberación), sino que rompe la relación espectador-actor, convirtiéndolo en una especie de diálogo común. Introduce, pues, en la historia del teatro universal, una especificidad latinoamericana. En Europa, sin embargo, esas técnicas fallan, y para que puedan funcionar Boal tiene que transformar el modelo en otro específicamente europeo: las técnicas del arcoíris del deseo y, más concretamente, del "policía en la cabeza". También ha construido nuevas formas teatrales para desarrollar la democracia, como el Teatro Legislativo, que deriva de otra especificidad latinoamericana como es las prácticas de democracia radical que se han 
desarrollado en distintos países. Se desarrolló, también, una filosofía de la historia, aunque relatos escénicos de la colonialidad y de la subalternidad no han aparecido en el teatro ampliamente. De hecho, se ha tratado de presentar un teatro de la identidad como sinónimo de crítico. Se puede encontrar denuncias del genocidio, de las barbaridades cometidas por los colonizadores, pero eso es lo que ha habido a lo largo de la historia de la humanidad (el idealismo humanista no sirve como teoría crítica); lo que no se cuenta es lo específico del genocidio en Latinoamérica. La filosofía de la historia que abre este grupo es una filosofía de la historia de la colonialidad. El discurso para la liberación, la crítica de los principios de la razón colonial, imperial, esto se ha tratado de poner en marcha problematizando el punto central de la razón colonial: el sujeto, desplazándolo al otro. Luis Valdéz (teatro campesino) escribía "Mi estética está basada en el nahui ollin, en el pensamiento Maya que dice: tú eres mi otro yo; si te amo y te respeto a ti, me amo y me respeto a mí, y si te hago daño a ti, me hago daño a mí". La otra forma ha sido construir una teoría de la dependencia: muchos intelectuales latinoamericanos empezaron a mostrar que el desarrollismo, el progreso de Latinoamérica, se basaba en siete tesis equivocadas que explican bien buena parte del bloqueo en que ha estado el discurso crítico en Latinoamérica.

\section{Radical historicidad latinoamericana}

Podemos establecer un marco de análisis de la historia latinoamericana a partir de las "Siete tesis equivocadas sobre América Latina”, que Rodolfo Stavenhagen publicó en 1981. Se enunciarán aquí las tesis solamente para que nos permitan situarnos histórica y socialmente. La primera dice que "Los países latinoamericanos son sociedades duales": "en los países latinoamericanos existen de hecho dos sociedades diferentes y hasta cierto punto independientes, aunque necesariamente conectadas: una sociedad arcaica, tradicional, agraria, estancada o retrógrada, y una sociedad moderna, urbanizada, industrializada, dinámica, progresista y en desarrollo. (...) Según esta tesis, cada una de las dos sociedades que se encuentran -y se enfrentan- así en cada uno de los países latinoamericanos tiene su dinámica propia”. Para Stavenhagen, sin embargo, esta tesis es falsa porque ninguna de las dos sociedades estaría separada, al contrario, estarían conviviendo y, más importante aún, porque los dos polos serían el resultado de un único proceso histórico. Este contratesis es importante porque nos permite estudiar la historia del teatro latinoamericano no como una 
expresión dual, por una parte, el ritual y por otra el teatro burgués, sino como el funcionamiento de una sola sociedad global. En ella estarían tantos las culturas "arcaicas" e "indígenas" como las "modernas". La historia de este teatro crítico se propondría como un único proceso histórico. En buena medida, esto es lo que ha estudiado Néstor García Canclini en su Culturas híbridas y en La globalización imaginada. Así "el tipo de relaciones que se estableció entre una metrópoli colonial y sus colonias se repitió dentro de los propios países coloniales, en las relaciones que se fueron desarrollando entre unos cuantos <polos de crecimiento> y el resto del país. Lo que España representaba para sus colonias, eso mismo representaban los centros de la Nueva España (y del resto de América Latina) con respecto a las zonas atrasadas y aisladas que los rodeaban".

La segunda tesis afirma que "el progreso en América Latina se realizaría mediante la difusión de los productos del industrialismo a las zonas atrasadas, arcaicas y tradicionales". En buena medida estas tesis proceden de las metrópolis. Stavenhagen dice que esta tesis es falsa por muchas razones, pero sobre todo porque simplemente observando lo que ha sucedido cuando han entrado esos productos, puede advertirse que no ha desaparecido la cultura de la pobreza, que no han cambiado los niveles de vida de esa gente: puede darse el caso de que en casas de una sociedad arcaica se tenga una televisión, una radio, pero eso no indica que haya desaparecido esa pobreza. Y esto es importante porque en muchos casos, cuando se representan obras de teatro que quieren denunciar el estado de miseria de las poblaciones latinoamericanas se hace hincapié en un tipo de cultura (la de la marginalidad), de la carencia, y no en otras propias del teatro crítico: la que encuentra en esa cultura de la pobreza por una parte, una condición histórica social (de dominación y explotación) y, por la otra, la consideración de que la marginalidad es una forma de estar ubicado en el sistema y, desde ahí, analizar las estrategias de supervivencia y las estrategias de cambio. Y eso porque "la tesis correcta sería: el progreso de las áreas modernas urbanas e industriales de América Latina se hace a costa de las zonas atrasadas, arcaicas y tradicionales. En otras palabras, la canalización de capital, materias primas, géneros alimenticios y mano de obra proveniente de las zonas "atrasadas" permite el rápido desarrollo de los "polos de crecimiento" y condena a las zonas proveedoras al mayor estancamiento y al subdesarrollo. La relación de intercambio entre los centros urbanos modernos y las zonas rurales atrasadas es desfavorable 
a éstas, como lo es para los países subdesarrollados en su conjunto la relación de intercambio entre ellos y los países desarrollados".

La tercera tesis señala que "la existencia de zonas rurales atrasadas, tradicionales y arcaicas es un obstáculo para la formación del mercado interno y para el desarrollo del capitalismo nacional y progresista”. Eso ya no es sólo un argumento de las metrópolis sino, también, de los gobiernos que sustituyen a las instituciones coloniales. A lo largo de la historia reciente del teatro latinoamericano han existido dos caminos para hacer creer esta tesis: uno, la necesidad de crear mecanismos externos de evaluación artística, y dos, la obligación de modernizar las culturas nacionales. Pero, como indica Stavenhagen "salvo raras excepciones, no existe en ninguna parte en América Latina un capitalismo nacional y progresista, ni existen las condiciones internacionales para que éste se desarrolle”. Esta tesis en realidad desconoce que los capitalismos llamados nacionales en realidad están cooptados. El caso más claro son las últimas décadas de neoliberalismo que desde EE.UU. se ha impuesto no sólo a Latinoamérica sino a toda Europa. Además, habría que preguntarse qué desarrollo, desarrollo para qué, etc. Esto enlaza con la cuarta tesis que plantea la lucha entre la burguesía nacional y el dominio de la oligarquía terrateniente, aspecto central en buena parte del teatro latinoamericano, que llama nuestra atención acerca de si las obras que presentan un proyecto progresista de desarrollo nacional están afirmando un discurso crítico sobre el dominio oligárquico. Un teatro histórico crítico tendría que mostrar, al contrario, que "la burguesía encuentra en la oligarquía terrateniente más bien un aliado para mantener el colonialismo interno, el cual en última instancia beneficia por igual a estas dos clases sociales”.

La quinta tesis dice que "El desarrollo en América Latina es creación y obra de una clase media nacionalista, progresista, emprendedora y dinámica, y el objetivo de la política social y económica de nuestros gobiernos debe ser estimular la "movilidad social" y el desarrollo de esta clase”. Esta idea de clase media está en discusión también en Europa. Stavenhagen la discute porque considera borrosa su definición. En todo caso, el desarrollo no es creación de esa clase sino de todo un despliegue de potencias que está en las tensiones que se dan en la estructura social. No debemos pensar que las clases sociales son las rentas que uno maneja, ni otros modelos de riqueza social. Yo tendería a clasificarlas a partir de la tesis marxista de 
que las clases se distinguen en función de si son dueñas o no de los medios de producción. Si controlan, si tienen, los medios de producción. En ese sentido, en el teatro ya hay un problema: los actores, los dramaturgos, los técnicos, sus cuerpos y su inteligencia son sus medios de producción y, por ello, serían dueños de los medios de producción, pero de medios de producción inmaterial; por eso, al mismo tiempo, actores, dramaturgos y técnicos necesitan ser contratados para producir un material (que se representará en un teatro: el actor en la escena; que se editará: la obra en una editorial; que requerirá medios técnicos: un espacio con focos, mesas de sonido, luces, etc.). Paradójicamente: tienen medios de producción inmaterial pero no de producción material. Lo fundamental es que esta clase media participa de un consenso político por el que los conflictos sociales son borrados (otra tesis que, de enunciarse, sería falsa pues el conflicto antagonista es constitutivo de la sociedad). Pero aquí es importante advertir que el teatro latinoamericano suele plantear este consenso, esta preeminencia de la clase media, como su forma de crítica, a pesar de que -claramente- no se justifique.

La sexta tesis plantea que "la integración nacional en América Latina es producto del mestizaje. Esta tesis es frecuente en los países que tienen problemas étnicos: aquellos con fuerte proporción de población indígena, y el Brasil con su población negra”, y continúa: “La falacia de esta tesis está en que el mestizaje biológico y cultural (proceso innegable en muchas partes de América Latina) no constituye, en sí mismo, una alteración de la estructura social vigente. Al igual que la tesis de la clase media, la del mestizaje atribuye a ciertos elementos de la población (definidos arbitrariamente, de acuerdo con criterios muy limitados) capacidades o características que no poseen o, si las tienen, son ajenas a los criterios biológicos o culturales que sirvieron para definirlos".

La última tesis "El progreso en América Latina sólo se realizará mediante una alianza entre los obreros y los campesinos, alianza que impone la identidad de intereses de estas dos clases". Esta tesis le parece falsa pero no porque no sea necesaria sino porque no se ha producido. La izquierda latinoamericana, dice Stavenhagen, desconoce que sólo hay una posibilidad mayoritaria, articulada, capaz de poner fuera de juego a los gobiernos burgueses o imperiales que es mediante esa alianza. 
Las tesis muestran un trabajo crítico sobre la realidad histórica de Latinoamérica que nos hacen pensar en la manera de plantear lo que debería afrontar, en el tema del teatro latinoamericano, otras tantas tesis falsas que se sostiene hoy en día.

Parecen importantes estas tesis para enunciar que cuando en unas obras de teatro latinoamericano se presentan aparentemente conflictos que pueden suscitar en nosotros la visión de ser un conflicto que no estaba en el teatro, o de desarrollar un discurso crítico sobre un momento histórico, en realidad podemos estar manifestando no una práctica de análisis crítico sino de idealismo.

\section{¿Qué sería una obra latinoamericana?}

¿Qué textos formarían parte de ese corpus? En una respuesta rápida se podría decir que lo conformarían las obras hechas por personas nacidas en Latinoamérica, lo que nos llevaría a un tipo de clasificación jurídica: el corpus estaría definido por la nacionalidad. ¿Qué sucede con las obras hechas en Latinoamérica: un francés, por ejemplo, que escribe sobre la dictadura de Pinochet, ¿o una rusa que lo hace sobre el feminicidio en Guatemala? Si se aceptasen, entonces tendríamos que hablar de un criterio de tematización. Más aún: ¿cabrían las obras de los exiliados? Pero si su formación y su desarrollo cultural se ha hecho en otros países fuera de Latinoamérica, ¿no se deberían considerar obras transterritoriales? ¿No pertenecerían a la cultura del país que les acoge? Es un problema aparentemente simple, pero en realidad muy complejo. ¿Serían autores latinoamericanos, personas nacidas fuera del territorio pero que viven aquí ya? ¿Y si la producción de la obra es un encargo de un teatro nacional o de una sala independiente de un país latinoamericano? ¿Depende del texto que saliera?

Otros problemas relacionados con éste aparecen cuando se trata de definir esencialmente lo latinoamericano, entonces se plantea que para que una obra pudiese calificarse así debería responder a unas raíces, o a una identidad latinoamericana. A esto se añade otras propuestas como la de responder a específicas técnicas escénicas latinoamericanas, y finalmente, se propone en ocasiones el asunto de la transculturización: la experiencia latinoamericana. 
¿Podría ser que un latinoamericano pudiera no saber escribir sobre Latinoamérica, o que la obra no pudiera reconocerse como latinoamericana? Un ejemplo sintomático es la obra del venezolano Rodolfo Santana Encuentro en un parque peligroso (1973-1989) cuya orientación artaudiana no parece ajustarse a ninguna de las razones anteriores por las que se podría hablar de teatro latinoamericano.

¿Lo son los montajes escénicos que latinoamericanizan una obra? ¿La convierten en latinoamericana? En las políticas teatrales de los gobiernos, ¿qué debería considerarse una programación latinoamericana? El Teatro Nacional de Venezuela llena sus temporadas con zarzuelas que no son latinoamericanas y, además, en las programaciones de la mayoría de los teatros nacional se incluyen textos del teatro universal (término con el que, generalmente, se quiere decir del teatro europeo y norteamericano). ¿Esos teatros estarían haciendo una programación anti-nacional o, mejor, no nacional?

A grandes rasgos, lo primero que sucede en el mundo del teatro cuando se producen las independencias es la construcción de los teatros nacionales. Esto también sucede en Europa. Alemania no tiene más que poco más que un siglo. Italia no tiene más que un siglo. Estamos acostumbrados a pensar que en Europa las naciones llevan formadas desde hace miles de años, pero no es así. Cuando se independiza y constituye la nación mexicana (1821) aún no existe Alemania (1871). Cuando la Constitución mexicana de 1857 denomina República al Estado recién creado, los estados que luego formarán Alemania son todavía monarquías. Esta idea acerca de los progresos, los desarrollos y los subdesarrollos está mal enfocada. Esto es lo que hay que pensar: en las articulaciones. Los teatros nacionales de entonces recurren a la idea de Latinoamérica, de la patria grande, para terminar con el discurso imperial, no porque busquen una identidad, sino porque tienen que construir una para oponerse al colonialismo. Pero es coyuntural. Ese es uno de los elementos que nos obliga a pensar la historia y los periodos teatrales como no cronológicos. Necesitamos comprender que cuando los teatros nacionales se inician a finales del siglo XIX y comienzos del XX, y luego se reabren en los años cincuenta, el concepto de teatro nacional es diferente y está funcionando de forma distinta en un momento y en otro. El proyecto inicial trata de buscar en las raíces 
tradicionales, populares, indígenas, intentan buscar -elementos incluso escénicos, incluso en los ritos- un material suficiente para sostener la nación frente a otras, incluso a costa de hacer cosas como deformar el modelo europeo (el sainete, el melodrama) de forma que se dote a éste de una especie de nuevo contenido latinoamericano. Pero en los años cincuenta ya no se quieren distinguir de los imperios coloniales, ahora lo que se quiere es universalizar, entrar en el desarrollo mundial, y es entonces cuando esa producción de los teatros incluye lo que llamaría la normalización del teatro latinoamericano. A esto corresponde obras como Medea mapuche (2000) de Juan Radrigán. Sin embargo, este encuentro de culturas a través del teatro tiene dos direcciones: se puede utilizar el mito grecolatino para dotar a los mapuches de cierta relevancia, o sencillamente se puede sepultar el mundo mapuche a costa del mito grecolatino. Parecería que se trataba de colocar lo mapuche en el ámbito de lo universal, pero este trabajo tiene dobleces imprevistos.

Si hacemos la cronología de los teatros nacionales no entendemos nada. Creemos que es una forma propia de crear el Estado, pero nada nos dice qué se está jugando en cada caso. Para eso debemos ir a las coyunturas, que es un específico momento histórico constituido por un nudo de determinaciones y condiciones que segrega, en el nivel ideológico, una producción específica que no se da en otros momentos. Los teatros experimentales en Bolivia, en Chile o en Argentina no emergen por voluntad propia, sino que lo hacen en determinadas situaciones históricas. No aparecen en los años cincuenta, pero sí en los sesenta. Otro caso: existe un teatro de tendencia anarquista en Argentina en los años treinta, un teatro obrero en los años veinte en Chile, un teatro social campesino en México en los treinta: coinciden, pero ¿no son historias diferentes? Tal vez no existe esa historia de las naciones, tal vez nos empeñamos en poner historia del teatro argentino, y eso funciona bien en el marco de la academia argentina, o para promocionar la dramaturgia argentina en las condiciones del campo artístico, pero no nos sirve para crear una historia del teatro crítico latinoamericano. Es posible, por el contrario, que entendamos mejor lo que sucede si pensamos qué tienen en común las obras que en los años veinte y treinta se caracterizan por una marcada tendencia crítica en la forma de un teatro proletario, obrero. ¿Qué tienen de común esas sociedades? ¿Por qué esos territorios están atravesados en secuencias coyunturales por los mismos problemas y la respuesta que da el teatro son las mismas? Algo hay que se escapa a la cronología y a los territorios, y eso es otro elemento a pensar. 
Así pues, el primer asunto es si realmente estamos en disposición de hablar de una latinoamericanidad. De nuevo chocamos con el asunto de la identidad y, sin embargo, la construcción de una latinoamericanidad se desarrolla en función de luchas y conflictos que exceden del marco de los conflictos de identidad. El filósofo Étienne Bailar escribe:

La historia de las naciones, empezando por la nuestra, se nos ha presentado siempre con las características de un relato que les atribuye la continuidad de un sujeto. De este modo, la formación de la nación aparece como la culminación de un "proyecto" secular, jalonado de etapas y de tomas de conciencia que los perjuicios de los historiadores presentarán como más o menos decisivas (¿dónde colocar los orígenes de Francia? ¿en los antepasados galos? ¿en la monarquía de los Capetos? ¿en la revolución de 1789? etc.); pero que, de todas formas, se inscriben en un esquema idéntico: el de la manifestación de la personalidad nacional. Una representación semejante constituye ciertamente una ilusión retrospectiva, pero traduce también realidades institucionales condicionantes. La ilusión durante siglos en un territorio más o menos estable, con una denominación más o menos unívoca, se transmiten una sustancia invariable. Consiste también en creer que esta evolución, cuyos aspectos seleccionamos retrospectivamente de forma que nos percibamos a nosotros mismos como su desenlace, era la única posible, representaba un destino. Proyecto y destino son las dos figuras simétricas de la ilusión de la identidad nacional (Balibar: 135-136).

Podemos cambiar el nombre de Francia por el de Chile, México, Brasil o Perú, con una territorialidad, con un horizonte común y con un sujeto de la nación: el sujeto chileno, el sujeto mexicano, el sujeto brasileño, o el sujeto peruano. Parece que, a lo largo de ese tiempo, aquellos que vivían ese desarrollo tenían conciencia de ser lo que son. Entonces, ¿para qué sirven las escuelas?, ¿para qué sirven los teatros nacionales?, ¿para qué sirve instalar en los teatros continuas referencias a nuestra sociedad, sino para insistir en que hay algo así como un sujeto histórico transtemporal que atraviesa durante siglo algo y que nos convierte en lo mismo?

Pongamos un ejemplo: alguien que conoce a su abuela materna y considera que tiene algún rasgo psicológico o biológico igual que ella. Lo define: "ser estructurada" (y, sin embargo, es un rasgo común a miles de personas). Se le pregunta si ese rasgo pertenece a su abuela o 
a sus padres, y cómo sabe que pertenece a su abuela. Contesta: "Porque siempre nos dicen que nos parecemos en eso". Siempre se lo ha dicho alguien. Pongamos que no conoció a su otra abuela, pero se le pide que imagine que no murió, sino que está aquí. Alguien es su abuela paterna, pero no la reconoce, no puede, porque -finalmente- el reconocimiento biológico, de esa transtemporalidad de su genealogía, no procede de uno, dado que se es independiente. Alguien ha tenido que construir un relato, normalmente su familia, para que esa persona lo crea, y lo ha hecho introduciendo elementos que los vinculan. Los teatros nacionales, en un determinado momento, hacen esto con el público. Necesitan transformar a pueblos diferentes en el pueblo chileno, el pueblo mexicano; necesita encontrar un relato que los incluya a todos, un relato coherente. Gran parte del teatro latinoamericano, como el europeo, es la construcción de ese relato, como hace igualmente el cine, el arte, etc. Si ahora le decimos a la nieta que sus padres le mintieron y que esa no era su abuela, ¿cómo podría mostrar que sí? Sólo estaría en disposición de hacerlo recurriendo a otro relato, buscando en lo biológico.

El segundo asunto, siguiendo con Balibar, nos plantea que lo que aparece después de la independencia son los Estados, los Estados-nación, que son un tipo de estructuras políticas. Es lo primero que se articula después del desarrollo del relato a través de lo que sería la ideología, es decir, la producción de sentido: tiene sentido hablar de un pueblo, de una identidad, de la historia, de un territorio, etc. Luego se produce el Estado, pero el que produce el Estado no es un pueblo que se autogobierna y, sin embargo, nadie cuestiona que de la independencia se vaya al Estado. Si se va al Estado no es por una relación causa-efecto, se va porque se ha conformado un tipo de sistema de poder que necesita legitimar un Estado, nunca el autogobierno. Ya vemos que, incuso, el relato que haría el teatro, un teatro crítico, en ese punto se resistiría y analizaría lo que está sucediendo en el proceso de configuración del Estado. El que no es crítico acompaña a esta formación del Estado y deja fuera la posibilidad del autogobierno que sería el tema, en ese tiempo, del teatro crítico. Esto significa, una vez más, que la crítica está determinada por la historicidad (coyuntura y determinaciones). Cuando se lee o se ve una obra de teatro que supuestamente es crítica porque habla de la independencia de México, por ejemplo, vemos a unos "prohombres" (¿dónde están las mujeres?) que reclaman la independencia de la colonia: esa escena que se 
nos presenta como progresista y crítica con la colonia, lo dicho, no nos dice que la otra opción pueda existir, el autogobierno, lo no dicho. En la escena IV de Nuestra América titulada "Independencia" se nos muestra con claridad, con la introducción de Gaspar Rodríguez de Francia, esta contradicción. La obra progresista que nos habla de una posición crítica con la colonialidad, es simultáneamente reaccionaria porque niega el autogobierno. En nuestros términos, la obra crítica desde una posición deja de serlo desde otra. De modo que ya podemos ver que nuestros criterios sobre el discurso crítico deben ser usados no en forma de relación causal sino dialéctica puesto que en la misma obra puede existir el elemento crítico y, al mismo tiempo, su contrario.

Esto es lo que se planteó Althusser, tomándolo de Freud, cuando trató de pensar la estructura de las determinaciones. Encontró un concepto, el ya mencionado de sobredeterminación, que le permitió comprender esa estructura. Normalmente cuando tratamos de explicar las cosas decimos, esto está determinado por, encontramos una causa que determina que se haya producido algo. $\mathrm{O}$ incluso decimos que no sólo hay una causa sino varias. Esto es clave para entender, por ejemplo, los cambios estéticos en el teatro latinoamericano: cuando decimos que se da un paso en el teatro latinoamericano de lo popular a lo culto, o de un tipo de estética realista a otra vanguardista, lo que suele decirse es que hay un “cansancio del realismo”. ¿Nadie se cansa de la televisión, pero sí del realismo? Este argumento es inadecuado e insostenible. También las recurridas respuestas del tipo "les interesa a los gobiernos", "es un asunto de mercado", etc. En realidad, necesitamos la sobredeterminación para explicar que esas determinaciones que funcionan están articuladas y son necesarias en esa coyuntura para producir ese hecho. Podemos entender los cambios que se producen en la historia del teatro solamente si vamos periodizando con una caracterización de este tipo, es decir, si nos alejamos de la idea de contar, por ejemplo, la historia del teatro argentino diciendo que entre tal año y tal otro se produce mayoritariamente un tipo de teatro

Si leemos los análisis típicos de Los invasores, se dice que es de un año, que pertenece a la generación realista, etc. y que trata de una invasión de una casa rica por un grupo de pobres. Nada que nos lleve más allá de los lugares comunes, salvo que empecemos a aplicar la mecánica crítica respecto a su incorporación al corpus latinoamericano, por ejemplo, en qué obra europea puede encontrarse esto: en ninguna. Dónde se ha visto, aunque pudiéramos hallar un caso parecido, que los invasores le presenten un programa revolucionario a los ricos en cuyo desarrollo deben integrarse. No los quieren matar, los quieren incorporar: es más, si no lo hacen vagarán por el mundo sin fin. En qué obra de teatro africano, europeo, asiático, aparece esto. Lo que tiene de latinoamericanidad esta obra no es que haya sido escrita por un chileno, ni siquiera el hecho de que las descripciones en donde pudiera ocurrir la acción de esta obra fueran de un barrio de Santiago. Justamente, la única prueba de latinoamericanidad de esta obra es el hecho de que sólo en Latinoamérica puede darse una situación así (todo lo que se cuenta). De nuevo, en el centro está la propuesta de la filosofía de la liberación de colocar en lugar del yo al otro: la polémica entre Meyer y China es del que defiende su yo, su casa, su empresa, el burgués; y el otro, que se nombra como el otro (uno cualquiera dice), no un personaje pobre (como el de la obra uruguaya), pero otro potenciado; no simplemente un pobre, que vive en una miseria, sino una miseria hecha carne por la historia, que viene con un programa político de liberación, con razones de sus miseria, y con un plan para salir de eso. Esto es lo insólito. Pero también lo sería que se escribiera en los años treinta. En Chile en los años treinta tampoco podría encontrarse esa obra porque el discurso político sería otro muy diferente. Es importante entender que esta resolución de un conflicto como el de Los invasores es el de un conflicto específico no de Chile sino de Latinoamérica en los años sesenta. Y cuando uno atraviesa el continente hasta México, en todos los territorios es posible encontrar algunas obras que definen así las relaciones, aunque no se formalice igual. 
realista, o describiendo las políticas teatrales del gobierno de Perón, o que la aparición del teatro independiente trasforma el panorama teatral en los sesenta. No se trata de componer un relato de lo sucedido, sino de hacer un relato explicativo. Diremos entonces que no es que haya habido un falso teatro social sino una determinada coyuntura histórica entre estos años que explica el teatro hecho y todas las producciones ideológicas que se han realizado y la manera en que han sido llevadas a cabo. Un ejemplo, tenemos una obra chilena, Desdicha Obrera (1921), de Luis Emilio Recabarren. Es una obra de teatro político. El patrón dice a la protagonista: si tú no aceptas el trabajo que te ofrezco tu madre se morirá. Y después, si no aceptas mis demandas sexuales perderás el trabajo, y consecuentemente, tu madre se morirá. Ella podría haber dicho que no pero su madre depende de ella. Se ve un conflicto histórico clásico: la propiedad privada de los medios de producción; y uno nuevo: el patriarcado. En un acto de resistencia, la protagonista mata al patrón. Por la misma época, en España, se representa una obra de Joaquín Dicenta, Juan José, estrenada en 1895. Es una pieza usada por agrupaciones sindicales socialistas, y convertida en una obra emblemática del teatro obrero que se hace en los años veinte en el marco de las celebraciones del primero de mayo. Qué cuenta esta obra: el trabajador de una hacienda se enfrenta al capataz que acosa a su mujer. Despedido, el obrero tiene que robar para sobrevivir y, finalmente, acaba en la cárcel. Escapa para vengarse de su mujer que, finalmente, está con el capataz. Un melodrama. Sólo un análisis coyuntura e histórico de la estructura de las determinaciones puede explicar la diferencia de las dos obras.

Volviendo a la cuestión de la latinoamericanidad, podemos decir que existe tal especificidad a condición de pensarla no como algo esencial sino radicalmente histórica. La teología de la liberación, la pedagogía del oprimido, la filosofía de la liberación, la cultura maya, etc. son cultura latinoamericana. Lo que hace latinoamericano al corpus de textos que constituiría el Teatro Crítico Latinoamericano no es que se haga en Latinoamérica (que sería un criterio aceptable pero probablemente poco riguroso) sino que se produce en un espacio territorial caracterizado por rasgos comunes (la colonialidad, la descolonización, el desarrollismo, el neoliberalismo) y con proyectos propios. Si se produjera lo que llamaba Samir Amín la desconexión, el corte con la colonia, probablemente aparecería otro tipo de cultura 
latinoamericana radicalmente distinta. La latinoamericanidad, en tanto que construcciones históricas, también puede desaparecer.

¿Cómo pensar esas determinaciones? Veamos un ejemplo simple: imaginemos un tubo puesto en vertical en el que metemos papel, y después lo llenamos de agua: depende de la cantidad de agua que echemos el que acabe el papel cayendo. Pero si no pongo suficiente agua puede que el agua no caiga y sea taponada por el papel. Tienen que ver con la cantidad y la calidad. Puedo poner más materiales, tela, más agua, más papel. Dependiendo de los materiales y de las cantidades se quedará de una determinada manera. Esta solidificación es lo que tratamos de pensar con el término coyuntura. Además, si elimino todos esos materiales, puedo echar leche, aceite, arena, etc. me va a producir diferentes colores y formas, dependiendo de la articulación (de cómo los combinemos) se quedará de una manera o de otra, se entenderá de una manera u otra.

Se trata de buscar cuál es la fundamentación de esa estructura social: de describir, analizar y explicar su articulación. Algunas preguntas posibles: ¿se incluirían las teatralidades y los rituales como parte de ese corpus? Forman parte de esta historicidad y de las coyunturas que marcan los cambios sociales. ¿Debemos seguir el modelo Hobsbawm que se basa en construir una historia que no sigue la de las naciones propiamente? ${ }^{9}$ Este historiador habla de que las naciones están integradas en un modo de producción que finalmente es el que domina todas estas coyunturas específicas que vemos. Último asunto: ¿se incluye en este corpus del teatro latinoamericano el teatro chicano?

\section{Un esquema general}

Volvamos al esquema 2. Nos permite resumir toda la complejidad de elementos y su relación (estructuración) que hemos utilizado hasta aquí y que consideramos necesario para el trabajo crítico: partimos de que una sociedad es un conjunto de culturas, esto es, son las condiciones de producción y reproducción del estado de cosas, de la vida cotidiana, que tiene un conjunto de objetivaciones que la cultura hace sobre sí misma o sobre otras cosas (la ciencia); las proyecciones de sentido que van conformando lo que significa cada cosa (la ideología); y los

${ }_{9}$ Para las tesis de Eric Hobsbawm puede verse Sobre la historia, Barcelona, Crítica, 2010 
juicios de valor sobre los actos (la moral), que - por cierto- no tiene voz propia. Cuando se escucha que algo no debe hacerse porque está mal, no habla la moral sino la ideología. Y, a veces, la moral habla por la ideología sustentándose en la ciencia. No tiene voz sino un juicio, positivo o negativo. Se incluye en la sociedad el territorio y la historia. Vemos también que la relación entre la Cultura 1, la Cultura 2 y la Cultura 3 son de sometimiento, de asimilación, etc., pero no tiene por qué hacerlo sobre toda la cultura, sino que puede producirse sólo en el espacio moral, etc. Estas interacciones se dan en el marco de varias culturas. Estas sociedades son formaciones sociales que, para nuestro trabajo crítico, se caracterizan por configurarse como semiosferas. También puede llamarse modo de producción en un sentido fuerte del término, y que afecta no sólo al aspecto económico sino a todos los elementos.

Ahora bien, la ciencia, ese discurso y proceso de objetivación que está inscrito en una sociedad, en una cultura, no puede trabajar desde fuera (no hay afuera), y por eso la ciencia establece unos controles contra la ideología (la filosofía) y contra la moral, y se separa de la cultura establecida y reproducida. Introduce, pues, un espacio liminar, una especie de umbral, un excedente, que le permite hacer el trabajo de objetivación general. Ciencia, ideología y moral se articulan, esto es, todas estas

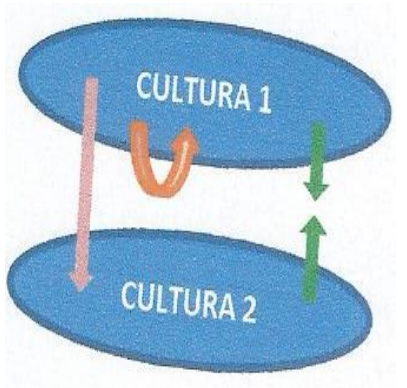
prácticas establecen relaciones entre ellas en función de diferentes parámetros (peso de las determinaciones de un tipo, cualidad de las mismas, coyuntura, etc.) que las modifican. A la totalidad de esas relaciones (siempre inestables), junto al territorio y la historia que son articulaciones de espacio y tiempo, la denominaremos estructura social. La manera en que lo haga nos da una serie de puntos de fijación provisionales, un estado de cosas. Esto es cambiante, está en tensión por las disfunciones, contradicciones, crisis, etc. Y por eso siempre está en cuestión, siempre está variando. Son siempre provisionales. Cuando actúa la ciencia, ésta establece una crítica general que en el momento en que introducimos una especie de análisis específico de estas articulaciones en este marco de la historia, que es lo que hace la crítica histórica (el materialismo histórico), encuentra coyunturas y sobredeterminaciones. Puede hacerse otro análisis distinto: la crítica de la cultura, que daría lugar al materialismo cultural (lo que se ha denominado estudios culturales), pero también puede hacerse una crítica del juicio y eso ocurre cuando analiza la moral, pero también una crítica de la ciencia, entonces se llama crítica epistemológica o crítica del conocimiento, si lo hace sobre los sujetos e individuos es la crítica psicoanalítica, etc. La ciencia tiene un proceso de producción 
específico y un objeto: el conocimiento. En el espacio ideológico incorporamos los tres ámbitos específicos del teatro: ritual, teatro y teatralidad, el teatro en concreto abre un campo artístico, distingue entre comercial y no comercial, culto y popular (aunque hablaríamos mejor de usos de códigos restringidos y códigos elaborados), dramático y posdramático, poéticas legítimas y no legítimas (cf. esquema 1), conservadoras y vanguardias, etc. Este teatro, que pasa obligatoriamente por el campo artístico (lo que no ocurre ni con el ritual ni con las teatralidades), es el que da lugar a una obra representacional (periodo moderno) o realización artística (posmoderno). Y aquí se encuentra con la crítica que viene de lo general y se especifica en el arte, que objetiva la obra explicando históricamente la matriz ideológica inconsciente que la produce, porque - no debe olvidarse- el arte es una forma ideológica.

Es importante distinguir las críticas positivistas e idealistas de las materialistas. Coinciden en el término, pero no tienen el mismo significado ni proceden de la misma manera. La crítica, como hemos visto, no es una opinión, porque la opinión no procede de la objetivación, de la ciencia. Nos puede informar sobre algunas cosas o ayudar a decidir qué vemos, pero nada más. Tampoco es un comentario, porque amplía lo que la obra dice sin que sea explicativo. Tampoco es una valoración, porque el juicio sobre la obra no nos dice nada sobre ella misma, ni sobre el mecanismo productivo. Ni es un acto de distinción, no se trata de hacer criterios para caracterizarla y etiquetarla. Todos los criterios que segregan estas formas de sentido común son criterios pragmáticos, pero no explicativos. La objetivación analiza y explica históricamente el conjunto de razones, ejercida por una matriz ideológica inconsciente, por las que se ha producido esta obra estableciendo un sentido.

Las matrices ideológicas, como los modos de producción ideológica, atraviesan un periodo largo de tiempo (larga duración). Así, la matriz colonial tiene 600 años; la matriz liberal, en su forma dominante, tiene 300, etc. Es cierto que siempre las matrices pueden sufrir cambios en las coyunturas. Por eso el historiador Immanuel Wallerstein, al tratar de dar cuenta de la historia del capitalismo, advierte que el capitalismo no es homogéneo y que se va conformando de manera diferente (como podría decirse del teatro dando lugar a obras, estilos, géneros y estilos distintos), aunque sostenido por la matriz de acumulación de capital, en distintas culturas. Por eso hay que tener siempre presente el análisis de coyunturas, la 
historicidad, etc. El sujeto individual moderno estaba sometido a la moral del trabajo y de la familia, pero el mismo capitalismo, cuando el proceso de acumulación se vio limitada, sufrió modificaciones que produjo un sujeto individual desligado de una moral moderna que es, al contrario, impulsado a otra moral "líquida", si se quiere así, más variable y flexible. Esto sucede también en el teatro: cuando se limita al espectador moderno y gran parte del público joven desaparece del teatro (por el cine, o simplemente no le atrae) aparece lo performativo que lo incorpora de nuevo. Esta crítica materialista ha elaborado toda una serie de categorizaciones que tienen que ver con su objeto de investigación y no con el género, los temas, etc. Lo que la ciencia requiere es un objeto de investigación, una problemática, una metodología y unas técnicas. En ese sentido, la crítica materialista ha rechazado las temáticas y géneros y propuesto otras.

\section{Categorías del teatro crítico}

Lo primero que aparece históricamente en relación con el discurso crítico es lo que se llama teatro social. No se trata de una decisión intelectual, sino que deriva del hecho de que al escenario sube, como resultado de una nueva situación histórica, el pueblo. No se trata de una clase social sino de un actor social que pone en escena la llamada entonces "cuestión social" y que aborda las consecuencias del desarrollo político, económico y cultural de la sociedad. Las consecuencias de ese desarrollo social (el capitalismo en este caso) son los niños trabajando en los telares, los obreros viviendo en condiciones terribles de miseria, algo que hasta entonces nadie en el teatro había mostrado como problema a representar escénicamente. Denunciaba, y por eso algunos llamaron teatro de denuncia, las condiciones de explotación terrible. Pero esto no tiene que ver con el teatro político, a pesar de que se confunde a menudo. Se visibiliza algo que estaba oculto, algo que nadie relataba, algo que se daba por bueno. Y, además, utilizaban recursos de las ciencias de entonces (biología, medicina, etc.) para justificar su ataque al trabajo de los niños. Hay más: todo lo que es la representación de condiciones miserables de vida: casas, hacinamiento, etc. pero este teatro tiene un problema: visibilizar no es analizar. De hecho, buena parte de este teatro fue reapropiado por el reformismo, esto es, antes estas consecuencias inasumibles tenemos que dar respuesta porque si no la conflictividad social se convierte en antagonismo. El teatro social, que se había planteado como una forma de denuncia sobre la sociedad, está obligado 
a convertirse en una declaración reformista. El segundo es que esa apropiación se convierta en capital rentable para unas determinadas ideologías: por ejemplo, todas esas casas de ayudas a los pobres que lo que hacen es contener el conflicto social y darle un sentido acrítico: esto es lo que te ha tocado, tú eres el único que puede salir de esto. Nosotros sólo podemos ayudarte. Esta actitud es lo que Brecht muestra en Santa Juana de los mataderos. Tiene otro problema más, y es que considera al individuo en tanto que ser humano, portador de una serie de derechos, de necesidades, que si no se cumplen este teatro tiene que reivindicar. Pero se puede quedar con que este teatro reclama derechos, necesidades, pero no nos dice en relación con qué estos derechos no se cumplen.

Con el teatro político estaríamos ante un discurso escénico que, utilizando los descubrimientos y lo que visibiliza el teatro social, va más allá. Absorbe el teatro social (lo subsume), lo incorpora, pero le da otra dimensión: explicando las razones de eso que se describe, razones que son fruto de relaciones de poder. Las considera resultado de unas lógicas antagonistas que materializan conflictos de dominación. El objeto específico del teatro político es el poder. Y por relaciones de poder establece tres tipos: el unidimensional, que podríamos simplificar con la fórmula: cuando alguien obliga a hacer algo a otra persona que no haría de ninguna manera a través de una acción directa (una amenaza, etc.); el bidimensional, en este caso A obliga a hacer a B algo que no haría de ninguna manera, a través de elementos interpuestos como son la moral, los valores, el hecho de que no eres reconocido. La tridimensional, $\mathrm{A}$ obliga a hacer a $\mathrm{B}$ algo que no haría de ninguna manera a través de un tercero. Ese tercero puede ser una situación, de una causa interpuesta (la privatización de la educación, por ejemplo). No se puede confundir una analítica, todos los mecanismos que se ponen en juego para el análisis de toda la obra, con la exposición de un problema de poder (no una escena, como en Antígona de Sófocles) ${ }^{10}$.

Los invasores, independientemente de la función ideológica que cumpla en su época, es una obra de teatro político. No sólo por el asunto que relata, una toma revolucionaria (que sobrepasa, pues, la tematización de los movimientos de pobladores) y que rompe las relaciones de dominación (este grupo controla la fábrica - esto es, los medios de producción-, la policía -los medios de control y monopolio de la violencia-, y el territorio), sino porque mediante el desarrollo dramático vamos conociendo la manera en que ejercen su poder los burgueses como Meyer: en primer lugar mediante la amenaza directa: cuando Meyer encuentra a China por primera vez le apunta con un revólver; en segundo lugar, con el poder de nombrar que China le señala constantemente ("¿Qué harían ustedes, si no tuvieran los nombres, para darle armado a todo esto?", y después “Usted lo llama crimen y con eso la cosa tiene ya otro nombre" (Ibíd.: 40). En tercer lugar, por su posición: "Soy Lucas Meyer, ¿entiendes lo que eso quiere decir (...) Llegué a tener doscientos hombres a mi cargo (...) Doscientos hombres con sus familias y vidas. ¡Todo aquí, en esta mano! Los he tomado y cambiado de un lugar a otro. Los he subido y bajado a mi antojo. Les he dado salario y ellos han comido" (Ibíd.: 68). En cuarto lugar, mediante técnica de ingeniería política y económica: el acaparamiento de la harina (control del hambre), el aumento artificial del precio de los fármacos, una educación trucada, el alza del precio de los alimentos (control de precios), criminalizando a los pobres calificándolos de sucios, borrachos, flojos, ladrones (Ibíd.: 7173). En quinto lugar, explotándolos y desahuciándolos (Ibíd.: 74-76).

10 Estudio más ampliamente el teatro político en La escena constituyente, Madrid, CDC, 2013 
La tercera categoría es el Teatro del común, que ya forma parte del teatro posmoderno (no como las otras que son modernas). Se trata de un proceso de construcción escénica (que usa habitualmente las teatralidades) que tiene por objeto establecer modelos de gobernanza de los bienes comunes, de los bienes comunales. No se trata sólo de un tema que lleva a la realización escénica o a una obra una problemática, sino que se conforma como modo de participación en los asuntos comunes: agua, energía, tierra, salud, etc. Son dispositivos de teatro del común gran parte de las actividades que genera la estética relacional, de los pueblos en transición, de las acciones de Greenpeace. Es como si este fuera el correspondiente teatro social del siglo XXI. Define estos bienes comunes y el conflicto sobre ellos, y pretende traspasar a la vida sus propuestas. Una de las tendencias es el Teatro Legislativo: la comunicación es un elemento central en este tipo de teatro: encontrarse y establecer una poética del encuentro. Se trata de traspasar las subjetividades individuales por las intersubjetividades.

Respecto al Teatro comunitario hay debates importantes y controvertidos. Aquí se propone, con un concepto no habitual, otro distinto al que, por ejemplo, se usa en Argentina. Frente al universalismo que declaraba la modernidad, este teatro se fija en el individuo local (tesis básica de la posmodernidad), que introduce como elemento fundamental el enriquecimiento de la vida cotidiana, de la vida en comunidad. Tienen que ver con un uso de los espacios. Lo más importante no es tanto lo que se proponga como obra como el hecho de que se está produciendo ahí, en comunidad. Concibe la idea de que es posible establecer un micromundo que ponga fuera de juego la semiosfera en la que vivimos. Frente a ese universo de signos que nos rodea desde que nacemos, este teatro trata de crear una alternativa de signos controlados por la comunidad. No sería un teatro de barrio, de población, de municipio, no es una fiesta de todos, ni una celebración conjunta. No es un teatro del común, de la comunitas (Expósito), sino un teatro que muestra lo que les hace estar en un proyecto colectivo: por ejemplo, el dolor, la cárcel, una carencia común. Este tiene su origen en las comunidades alternativas de los sesenta, en los pueblos emancipados. Se potencia la unión entre los habitantes de una comunidad. Su dispositivo escénico es un teatro de situaciones que propone dialogar en torno a eso que son estrategias de culturación. 
Finalmente, estaría el teatro testimonial que tiene muchos problemas respecto a las terminologías. Se llama así al teatro crítico que trata de presentar en la escena o en el acto performativo una salida de la ficción teatral en beneficio de la enunciación que hace un sujeto vital que posee una memoria y que la historia, generalmente, no le ha dejado lugar alguno. En su especificidad, su introspección es lo que permite establecer un escenario de la memoria que lo presente como la antítesis de lo general. El teatro testimonial tiene su objeto en el relato o las acciones (rituales, teatralidades) que abordan con profundidad el lugar de donde procede nuestra experiencia y, sobre todo, nuestra vida realizada. El contexto forma parte del dispositivo escénico o de significación.

Todos estos niveles, naturalmente, no aparecen en estado puro, siempre los vemos mezclados.

\section{Final}

Como se puede ver queda casi todo por hacer: en primer lugar, elaborar un corpus; para lo que se necesita definir teóricamente cómo se van a tratar los textos teatrales (obras y realizaciones). En segundo lugar, establecer un criterio de periodización mediante la demarcación de coyunturas. Finalmente, abrir un espacio permanente de encuentro, discusión y archivo de todos estos materiales. La Historia del Teatro Crítico Latinoamericano está aún por hacer. Como escribió Mariátegui:

El escenario teatral es uno de los escenarios más atrayentes $\boldsymbol{y}$ más vastos de esta época y de sus conflictos. Todas las inquietudes, los contrastes y los problemas de la historia contemporánea se reproducen en el mundo del teatro. El Teatro, como el Arte en general, carece actualmente de un estilo, de un rumbo, de un espíritu únicos. Se descompone, como la fatigada civilización occidental, en diversos estados de ánimo. Se fragmenta en numerosas escuelas, formas y tendencias. Semeja una inmensa feria cosmopolita donde toda moda es precaria, toda filosofía es efímera y todo color es tornadizo. No se puede encerrar dentro de dos o tres definiciones el carácter de este teatro. $Y$ es que no tiene un carácter sino varios que se repelen y se confunden, se mezclan y se excluyen. Hay que explorar, una por una, sus facetas. Aunque entonces se corre el riesgo dé extraviarse en un laberinto de teorías y de búsquedas y de senderos: teatro sintético, teatro experimental, teatro de color, etc. Pero, entre 
tanta complejidad y tanta movilidad, aparece siempre algún porfiado elemento esencial, alguna línea persistente, alguna nota constante.

\section{APÉNDICE: ELEMENTOS PARA UN ANÁLISIS DE UN TEXTO TEATRAL SOBRE EL TEXTO}

Título de la obra/espectáculo:

Datos sobre autoría:

Fecha de escritura/edición/representación:

Antecedentes temáticos/estéticos:

Canon estético al que se adscribe el texto:

Resumen del texto:

\section{SOBRE LA DIMENSIÓN CULTURAL DEL TEXTO}

Definición del ámbito socio-cultural de la obra:

Problemas y aspecto de la realidad tratados:

Auditorio al que se dirige:

Códigos más relevantes que aparecen en la obra:

Recepción del texto: 


\section{SOBRE EL CONTEXTO}

Condiciones históricas, nacionales e internacionales:

Condiciones políticas e ideológicas:

Condiciones culturales coexistentes (se incluye el contexto teatral):

\section{ANÁLISIS DEL TEXTO}

El imaginario social y la estructura del mundo que propone el texto:

Sistema de valores que sustenta:

Conflictos dramáticos más relevantes:

Disposición temporal de la historia (real/imaginario/hipotético):

Disposición espacial de la historia (real/imaginaria/hipotética):

Modo de construcción dramática (movimiento y progresión dramática):

Personajes (definición y tratamiento):

Lenguas de la obra:

Dispositivos escénicos:

Determinación crítica del texto: 


\section{Retóricas:}

Valoración personal:

\section{Referencias bibliográficas}

Althusser, Louis (1988), La revolución teórica de Marx, México D.F., Siglo XXI.

Balibar, Etienne y Wallerstein, Immanuel (1991), Raza, nación, clase, Madrid, IEPALA.

Bellini, Giuseppe (1985), Historia de la literatura hispanoamericana, Madrid, Castalia.

Donghi, Tulio Halperin (1986), Historia contemporánea de América Latina, Madrid, Alianza Editorial.

De Toro, Fernando (1987), Brecht en el teatro hispanoamericano contemporáneo, Buenos Aires, Argentina.

García Canclini, Néstor (1990), Culturas híbridas, México D.F., Grijalbo.

(1999), La globalización imaginada, Buenos Aires, Paidós.

(2007), Las culturas populares en el capitalismo, México D.F.,

Grijalbo.

Garzón, Francisco (coord.) (1978), El teatro latinoamericano de creación colectiva, La Habana, Casa de las Américas.

Galeano, Eduardo (1971), Las venas abiertas de América Latina, Madrid, Siglo XXI.

(1982-1986), Memoria del fuego, Madrid, Siglo XXI, 3 vv.

Garcés, Mario (2002), Tomando su sitio, Santiago de Chile, LOM.

Geirola, Gustavo (2000), Teatralidad y experiencia política en América Latina, Irvine, Gestos.

Guattari, Félix (1996), Caosmosis, Buenos Aires, Manantial.

Guattari, Félix y Rolnik, Suely (2006), Micropolíticas, Madrid, Traficantes de Sueños. 
Gómez, Juan Carlos (2004), "Democracia vs propiedad privada", Tres décadas después, Santiago de Chile, Arcis, pp. 27-72.

Löwy, Michael (1982), El marxismo en América Latina, México, Era.

Mignolo, Walter (2007), La idea de América Latina, Barcelona, Gedisa.

Muguercia, Magaly (ed.) (1996), Pedagogía y experimentación en el teatro latinoamericano, México, Escenología.

Chile, RIL, 2 vv. (2010-2015), Teatro latinoamericano del siglo XX, Santiago de

Pianca, Marian (1989), "Postcolonial Discourse in Latin American Theatre. Theatre Journal. Vol. 41, No. 4, págs. 515-523

Proaño Gómez, Lola (2007), Poéticas de la globalización en el teatro latinoamericano, Irvine, Gestos.

Rizk, Beatriz (2002), Teatro y diáspora. Testimonios escénicos latinoamericanos, Irvine, Gestos.

Rojo, Sara (2010), Teatro y pulsión Anárquica. Santiago de Chile, USACH.

Stavenhagen, Rodolfo (1981), "Siete tesis equivocadas sobre América Latina" en Sociología y Subdesarrollo, México D.F., Nuestro Tiempo, págs. 15-84. Recuperado de: https://pensamientolatinoamericanounmdp.files.wordpress.com/2011/10/pc3a1ginas-destavenhagen-sietetesisequivocadassobreamricalati.pdf

Taylor, Diana (1991), Theatre of Crisis: Drama and Politics in Latin America. Lexington: University Press of Kentucky.

Versényi, Adam (1996), El teatro en América Latina, Cambridge University Press.

Villegas, Juan (1997), Para un modelo de historia del teatro, Irvine, Gestos.

(2005), Historia multicultural del teatro y las teatralidades en América Latina, Buenos Aires, Galerna.

De Vicente Hernando, César de (2013), La escena constituyente, Madrid, Centro de Documentación Crítica.

Documentación Crítica. (2017), La dramaturgia política, Madrid, Centro de VV.AA. (1988), Escenarios de dos mundos, Madrid, Centro de Documentación Teatral, 4 vV. 
Wolff, Egon (1999) Los invasores/ José, Santiago, Pehuén. 